\title{
Human T-bet governs innate and innate-like adaptive IFN- $\gamma$ immunity against mycobacteria
}

Rui Yang ${ }^{1, @}$, Federico Mele ${ }^{2, *}$, Lisa Worley ${ }^{3,4, *}$, David Langlais ${ }^{5,6, *}$, Jérémie Rosain ${ }^{7,8, *}$, Ibithal Benhsaien ${ }^{9,10,}$, Houda Elarabi ${ }^{11, \S}$, Carys A. Croft ${ }^{12,13,14, \S}$, Jean-Marc Doisne ${ }^{12,13, \S}$, Peng Zhang ${ }^{1,}$, Marc Weisshaar ${ }^{15, \S}$, David Jarrossay ${ }^{2,}$, Daniela Latorre ${ }^{15}$, Yichao Shen ${ }^{1}$, Jing Han ${ }^{1}$, Conor Gruber ${ }^{16,17,18}$, Janet Markle ${ }^{1}$, Fatima Al Ali ${ }^{19}$, Mahbuba Rahman ${ }^{19}$, Taushif Khan ${ }^{19}$, Yoann Seeleuthner ${ }^{7,8}$, Gaspard Kerner ${ }^{7,8}$, Lucas T. Husquin ${ }^{20}$, Julia L. Maclsaac ${ }^{21}$, Mohamed Jeljeli ${ }^{22}$, Fatima Ailal ${ }^{9,10}$, Michael S. Kobor ${ }^{21}$, Carmen Oleaga-Quintas ${ }^{7,8}$, Manon Roynard ${ }^{7,8}$, Mathieu Bourgey ${ }^{6,23}$, Jamila El Baghdadi ${ }^{24}$, Stéphanie Boisson-Dupuis ${ }^{1,7,8}$, Anne Puel ${ }^{1,7,8}$, Fréderic Batteux ${ }^{22}$, Flore Rozenberg ${ }^{25}$, Nico Marr ${ }^{19,26}$, Qiang Pan-Hammarström ${ }^{27}$, Dusan Bogunovic ${ }^{16,17,18}$, Lluis Quintana-Murci ${ }^{20,28}$,

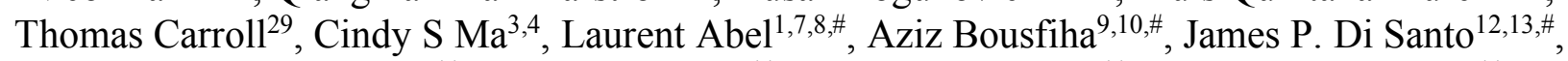
Laurie H Glimcher ${ }^{30,31, * *}$, Philippe Gros ${ }^{6,32 * *}$, Stuart G Tangye ${ }^{3,4, * *}$, Federica Sallusto ${ }^{2,15, * *}$,

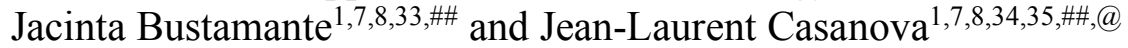

${ }^{1}$ St Giles Laboratory of Human Genetics of Infectious Diseases, Rockefeller Branch, Rockefeller University, New York, NY, USA

${ }^{2}$ Center of Medical Immunology, Institute for Research in Biomedicine, Faculty of Biomedical Sciences, University of Italian Switzerland (USI), Bellinzona, Switzerland.

${ }^{3}$ Immunology Division, Garvan Institute of Medical Research, Darlinghurst, Australia

${ }^{4}$ St Vincent's Clinical School, Faculty of Medicine, UNSW Sydney, Darlinghurst , Australia

${ }^{5}$ Department of Human Genetics, Department of Microbiology and Immunology, McGill University, Montreal, QC, Canada

${ }^{6}$ McGill University Genome Center, McGill Research Centre on Complex Traits, Montreal, QC, Canada

${ }^{7}$ Laboratory of Human Genetics of Infectious Diseases, Necker Branch, INSERM UMR 1163, Necker Hospital for Sick Children, Paris, France, EU

${ }^{8}$ Paris University, Imagine Institute, Paris, France, EU

${ }^{9}$ Laboratory of Clinical Immunology, Inflammation and Allergy, Faculty of Medicine and Pharmacy of Casablanca, King Hassan II University, Casablanca, Morocco

${ }^{10}$ Clinical Immunology Unit, Department of Pediatric Infectious Diseases, Children's Hospital, CHU Averroes, Casablanca, Morocco

${ }^{11}$ Pediatrics Department, Hassan II Hospital, Dakhla, Morocco

${ }^{12}$ Innate Immunity Unit, Institut Pasteur, 75724 Paris, France, EU

${ }^{13}$ Inserm U1223, 75015 Paris, France, EU

${ }^{14}$ Université de Paris, Sorbonne Paris Cité, Paris, France, EU

${ }^{15}$ Institute of Microbiology, ETH Zurich, Switzerland

${ }^{14}$ Department of Immunology, Institut Pasteur, Paris, France, EU

${ }^{16}$ Department of Microbiology, Icahn School of Medicine at Mount Sinai, NY, USA

${ }^{17}$ Department of Pediatrics, Icahn School of Medicine at Mount Sinai, NY, USA

${ }^{18}$ The Mindich Child Health and Development Institute, Icahn School of Medicine at Mount Sinai, NY, USA

${ }^{19}$ Research Branch, Sidra Medicine, Doha, Qatar

${ }^{20}$ Unit of Human Evolutionary Genetics, CNRS UMR2000, Institut Pasteur, Paris, France, EU 
$1 \quad{ }^{21}$ BC Children's Hospital Research Institute, Department of Medical Genetics, University of

2 British Columbia, Vancouver, Canada

$3 \quad{ }^{22}$ Immunology Laboratory, Cochin Hospital, AH-HP, Paris, France, EU

$4 \quad{ }^{23}$ Canadian Centre for Computational Genomics, Montreal, QC, Canada

$5 \quad{ }^{24}$ Genetics Unit, Military Hospital Mohamed V, Rabat, Morocco

$6 \quad{ }^{25}$ Virology Laboratory, Cochin Hospital, AH-HP, Paris, France, EU

$7 \quad{ }^{26}$ College of Health and Life Sciences, Hamad Bin Khalifa University, Doha, Qatar

$8 \quad{ }^{27}$ Department of Biosciences and Nutrition, Karolinska Institutet, Stockholm, Sweden, EU

$9 \quad{ }^{28}$ Human Genomics and Evolution, Collège de France, Paris, France, EU

$10{ }^{29}$ Bioinformatics Resource Center, The Rockefeller University, New York, USA

$11{ }^{30}$ Department of Cancer Immunology and Virology, Dana-Farber Cancer Institute and Harvard

12 Medical School, Boston, USA

$13{ }^{31}$ Department of Medicine, Harvard Medical School and Brigham and Women's Hospital, Boston,

14 USA

$15 \quad{ }^{32}$ Department of Biochemistry, McGill University, Montreal, QC, Canada.

$16{ }^{33}$ Study Center for Primary Immunodeficiencies, AP-HP, Necker Children Hospital, Paris, France, 17 EU

$18{ }^{34}$ Pediatric Hematology-Immunology Unit, Necker Hospital for Sick Children, AP-HP, Paris, 19 France, EU

$20 \quad{ }^{35}$ Howard Hughes Medical Institute, New York, NY, USA

$\S, *, * *, \#, \# \#$ These authors contributed equally

$23 @$ Correspondence: ryang@rockefeller.edu and casanova@rockefeller.edu 


\section{Author contributions}

2 R.Y., J.B. and J.-L.C. conceptualized the study, designed the experiments, interpreted the data, 3 and wrote the manuscript. R.Y., G.K. and J.R. identified and validated the patient's mutation. 4 Yoa.S., G.K. and L.A. performed genome-wide linkage analysis. R.Y. tested the mutation, 5 performed T-bet overexpression experiments, characterized the T-bet function in patient-derived cell lines and primary cells, performed T-bet complementation in $\mathrm{CD}^{+} \mathrm{T}$ cells, RNA-seq experiments, and omni-ATAC-seq experiments, ex vivo and in vitro activation experiments. Dav.L., M.B. and P.G. performed scRNA-seq experiments and analyzed the data. L.W, C.S.M. and S.G.T. performed immunophenotyping of PBMCs and $\mathrm{CD}^{+} \mathrm{T}$ cell ex vivo stimulation and in vitro differentiation, and analyzed the data. R.Y. and P.Z. analyzed RNA-seq data. R.Y., J.L.M., M.S.K., P.Z., L.T.H., and L.Q.M. performed and analyzed Epic-DNA methylation array analyses.

12 M.J., F.B., and F.R. performed clinical serological tests. R.Y., F.M., D.J., M.W., Dan.L., and F.S. performed and analyzed memory $\mathrm{CD}^{+}$T-cell libraries. C.A.C., J.-M.D., and J.P.D. performed and analyzed immunophenotyping for NK cell and ILCs by flow cytometry. H.E., I.B., F.A., A.B. and J.B. took care of the patient. J.E.B. contributed North African exomes to our in-house database. R.Y., J.M., and Yic.S. designed and generated mutant T-bet plasmids. R.Y. and J.H. performed and analyzed live BCG stimulation of PBMC experiments and $\mathrm{V} \delta 2^{+} \gamma \delta \mathrm{T}$ expansion experiments. R.Y., C.G., and D.B. performed and analyzed CyTOF mass cytometry experiments. F.A.A., Mah.R., T.K., and N.M. performed and analyzed the phage immunoprecipitation-sequencing experiments. C.O-.Q., Man.R., R.Y., and J.B. prepared DNA, plasma and PBMCs from the patient, his family and healthy donors. T.C. and R.Y. analyzed omni-ATAC-seq data. S.B-.D., A.P., Q,P-.H, L.H.G., P.G., S.G.T., F.S., J. B., and J.-L.C. supervised the study and made significant intellectual contributions. All authors provided input on the final manuscript. 


\section{Summary}

Inborn errors of human IFN- $\gamma$ immunity underlie mycobacterial disease. We report a

3 patient with mycobacterial disease due to an inherited deficiency of the transcription factor T-bet.

4 This deficiency abolishes the expression of T-bet target genes, including IFNG, by altering

5 chromatin accessibility and DNA methylation in $\mathrm{CD}^{+} \mathrm{T}$ cells. The patient has profoundly

6 diminished counts of mycobacterial-reactive circulating NK, invariant NKT (iNKT), mucosal-

7 associated invariant $\mathrm{T}$ (MAIT), and $\mathrm{V} \delta 2^{+} \gamma \delta \mathrm{T}$ lymphocytes, and of non-mycobacterial-reactive

8 classic $\mathrm{T}_{\mathrm{H}} 1$ lymphocytes, the remainders of which also produce abnormally low amounts of IFN-

$9 \gamma$. Other IFN- $\gamma$-producing lymphocyte subsets however develop normally, but with low levels of

10 IFN- $\gamma$ production, with exception of $\mathrm{V} \delta 2^{-} \gamma \delta \mathrm{T}$ lymphocytes, which produce normal amounts of

11 IFN- $\gamma$ in response to non-mycobacterial stimulation, and non-classic $\mathrm{T}_{\mathrm{H}} 1\left(\mathrm{~T}_{\mathrm{H}} 1^{*}\right)$ lymphocytes,

12 which produce IFN- $\gamma$ normally in response to mycobacterial antigens. Human T-bet deficiency

13 thus underlies mycobacterial disease by preventing the development of, and IFN- $\gamma$ production by,

14 innate (NK) and innate-like adaptive lymphocytes (iNKT, MAIT, and $\mathrm{V} \delta 2^{+} \gamma \delta \mathrm{T}$ cells), with

15 mycobacterial-specific, IFN- $\gamma$-producing, purely adaptive $\alpha \beta \mathrm{T}_{\mathrm{H}} 1^{*}$ cells unable to compensate for

16 this deficit. 


\section{Introduction}

In the course of primary infection, life-threatening disease in otherwise healthy children,

3 adolescents, and even adults, can result from monogenic inborn errors of immunity, which display

4 genetic heterogeneity and physiological homogeneity (Casanova, 2015b, 2015a). Mendelian

5 susceptibility to mycobacterial disease (MSMD) is characterized by a selective, inherited

6 predisposition to clinical disease caused by weakly virulent mycobacteria, such as Mycobacterium

7 bovis Bacille Calmette-Guérin (BCG) vaccines and environmental mycobacteria (Rosain et al.,

8 2019). Patients are also vulnerable to bona fide tuberculosis. Patients with typical, "isolated"

9 MSMD are rarely prone to other infectious agents, with the exception of Salmonella and

10 occasionally other intra-macrophagic bacteria, fungi, and parasites (Bustamante et al., 2014;

11 Rosain et al., 2019). Patients with atypical, "syndromic" MSMD often display other clinical

12 phenotypes, infectious or otherwise. MSMD, both "isolated" and "syndromic", displays a high

13 level of genetic heterogeneity, with causal mutations in 15 genes, and additional allelic

14 heterogeneity, resulting in 30 different disorders (Table S1). However, there is also physiological

15 homogeneity, as all known genetic causes of MSMD affect IFN- $\gamma$-dependent immunity (Boisson-

16 Dupuis et al., 2018; Bustamante et al., 2014; Kong et al., 2018; Martínez-Barricarte et al., 2018;

17 Rosain et al., 2019). Mutations of IL12B, IL12RB1, IL12RB2, IL23R, TYK2, ISG15, RORC,

$18 I K B K G$ (NEMO), IRF8, and SPPL2A impede IFN- $\gamma$ production by innate and adaptive immune

19 cells, whereas mutations of IFNGR1, IFNGR2, STAT1, JAK1, and CYBB impair cellular responses

20 to IFN- $\gamma$ (Fig. S1A). The clinical penetrance and severity of MSMD depend strongly on genetic

21 etiology and they increase with decreasing levels of IFN- $\gamma$ activity (Dupuis et al., 2000). Four

22 etiologies also result in an impairment of immunological circuits other than the IFN- $\gamma$ circuit,

23 accounting for "syndromic" MSMD in the corresponding patients (Rosain et al., 2019). 
1 Collectively, these studies revealed the crucial role of human IFN- $\gamma$ in antimycobacterial immunity and its redundancy for immunity against many other pathogens.

The cellular basis of MSMD in patients with impaired responses to IFN- $\gamma$ involves

4 mononuclear phagocytes. The ability of these cells to contain the ingested mycobacteria depends on their activation by IFN- $\gamma$ (Nathan et al., 1983). The cellular basis of MSMD in patients with

6 impaired IFN- $\gamma$ production is poorly understood, as most types of lymphocytes can produce IFN-

$7 \gamma$ (Wilson and Schoenborn, 2007). Some genetic etiologies of MSMD affect some lymphocyte

8 subsets more than others. ISG15 deficiency preferentially impairs the production of IFN- $\gamma$ by NK

9 cells (Bogunovic et al., 2012; Zhang et al., 2015). IL-12R $\beta 2$ deficiency preferentially impairs the

10 production of IFN- $\gamma$ by NK, B, $\gamma \delta$ T, classic $\alpha \beta$ T cells, ILC1, and ILC2 cells, whereas IL-23R

11 deficiency preferentially impairs that by invariant NKT (iNKT) and mucosal-associated invariant

12 T (MAIT) cells, and both IL-12R $\beta 1$ and TYK2 deficiencies impair both the IL-12- and IL-23-

13 dependent subsets (Boisson-Dupuis et al., 2018; Martínez-Barricarte et al., 2018). SPPL2a and

14 IRF8 deficiencies selectively impair the production of IFN- $\gamma$ by CD4 ${ }^{+} \mathrm{CCR}^{+} \mathrm{T}_{\mathrm{H}} 1\left(\mathrm{~T}_{\mathrm{H}} 1^{*}\right)$ cells

15 (Hambleton et al., 2011; Kong et al., 2018), a $\mathrm{T}_{\mathrm{H}} 1$ cell subset enriched in Mycobacterium-specific

16 effector cells, whereas CCR6- $\mathrm{T}_{\mathrm{H}} 1$ cells do not respond to mycobacteria (Acosta-Rodriguez et al.,

17 2007). ROR $\gamma /$ ROR $\gamma$ T deficiency impairs the development of iNKT and MAIT cells, and also

18 decreases the production of IFN- $\gamma$ by $\gamma \delta \mathrm{T}$ and $\alpha \beta \mathrm{T}_{\mathrm{H}} 1 *$ cells (Okada et al., 2015). Interestingly,

19 although the lack of both $\alpha \beta \mathrm{T}$ and $\gamma \delta \mathrm{T}$ cells in SCID patients underlies BCG disease (Casanova

20 et al., 1995), most, if not all other deficits of antigen-specific $\alpha \beta$ T-cell responses, whether affecting

21 only $\mathrm{CD}^{+}{ }^{+}$or $\mathrm{CD} 8^{+} \mathrm{T}$ cells, such as HLA-II or HLA-I deficiency, typically do not (Table S2).

22 Moreover, selective deficiencies of NK or iNKT cells do not confer a predisposition to

23 mycobacterial disease (Casey et al., 2012; Cottineau et al., 2017; Gineau et al., 2012; Hughes et 
1 al., 2012; Latour, 2007; Locci et al., 2009; Morgan et al., 2011; Tangye et al., 2017). The nature

2 of the IFN- $\gamma$-producing innate, innate-like adaptive, and purely adaptive lymphocyte subsets

3 indispensable for antimycobacterial immunity, either alone or in combination, therefore remains

4 largely unknown. No genetic cause has yet been identified for half the MSMD patients. We

5 therefore sought to discover a new genetic etiology of MSMD that would expand the molecular

6 circuit controlling human IFN- $\gamma$ immunity while better delineating the cellular network involved. 


\section{Results}

\section{Identification of an MSMD patient homozygous for an indel variant of $T B X 21$}

We studied a three-year-old boy ("P”) born to first-cousin Moroccan parents (Fig. 1A). He

4 suffered from disseminated BCG disease (BCG-osis) following vaccination at the age of three

5 months. He also had persistent reactive airway disease (RAD), but was otherwise healthy

6 (Supplementary Material - Case Report). He did not suffer from any other severe infectious

7 diseases despite documented (VirScan) infection with various viruses, including Epstein-Barr

8 virus (EBV), human cytomegalovirus (CMV), roseola virus, adenoviruses A, B, C and D, influenza

9 virus A, rhinovirus A, and bacteria, such as Streptococcus pneumoniae and Staphylococcus aureus

10 (Fig. S1B). We hypothesized that $\mathrm{P}$ had an autosomal recessive (AR) defect. We performed whole-

11 exome sequencing (WES) on $\mathrm{P}$, his unaffected brother, and both parents. Genome-wide linkage

12 (GWL) analysis revealed 32 linked regions (LOD score $>1.3$ and size $>500 \mathrm{~kb}$ ) under a model of

13 complete penetrance (Fig. S1C). In these linked regions, there were 15 rare homozygous non-

14 synonymous or essential splicing variants in 15 different genes (minor allele frequency, MAF <

150.003 in gnomAD v2.1 and 1000 Genomes Project, including for each major ancestry) with a

16 combined annotation-dependent depletion (CADD) score above their mutation significance

17 cutoffs (MSC) (Consortium, 2015; Itan et al., 2016; Kircher et al., 2014; Zhang et al., 2018) (Fig.

18 S1D, Table S3). After the exclusion of genes with other predicted loss-of-function (LOF) variants

19 with a frequency greater than $0.5 \%$ in gnomAD, 12 candidate genes remained (Table S3). The

20 c.466_471delGAGATGinsAGTTTA insertion and/or deletion (indel) variant of TBX21 (T-box

21 protein 21 , or T-box, expressed in T cells, T-bet) was the candidate variant predicted to be the

22 most damaging (Kircher et al., 2014). Moreover, based on connectivity to IFNG, the central gene

23 of the entire network of all known MSMD-causing genes (Itan et al., 2013, 2014), TBX21 was the 
1 most plausible candidate gene (Table S4). T-bet is a transcription factor that governs the

2 development or function of several IFN- $\gamma$-producing lymphocytes in mice, including $\mathrm{T}_{\mathrm{H}} 1$ cells

3 (Lazarevic et al., 2013; Szabo et al., 2000, 2002). These findings suggested that homozygosity for

4 the rare indel variant c.466_471delGAGATGinsAGTTTA of TBX21 is MSMD-causing. We

5 investigated this variant according to the guidelines for genetic studies of single patients (Casanova

6 et al., 2014). Sanger sequencing confirmed that P carried the indel variant in exon 1 of TBX21

7 whereas his unaffected brother was homozygous wild-type (WT/WT) and both parents were

8 heterozygous (WT/M) (Fig. S1E). A closely juxtaposed 12-nucleotide (nt) region identical to this

9 variant sequence was detected 8-nt upstream from the variant, and may have served as a template

10 for the generation of this variant (Fig. S2A). The variant did not alter the exon 1-exon 2 junction

11 of the $T B X 21$ mRNA in EBV-transformed B (EBV-B) cells or peripheral blood mononuclear cells

12 (PBMCs) (Fig. S2B - D). The variant present in P thus resulted in the replacement of E156 and

13 M157, two amino acids that are highly conserved across different species and among other

14 paralogs of T-box transcription factors, with S156 and L157 (Fig. 1B and Fig. S3A).

\section{Overexpressed mutant T-bet is LOF}

We investigated the expression of the mutant allele (Mut), by overexpressing empty vector

18 (EV), and vectors containing the WT or Mut allele, or negative controls with the T-box domain

19 deleted (T-del) or K314R, the human ortholog of a known LOF mouse mutant, in human

20 embryonic kidney (HEK) 293T cells (Jang et al., 2013). The production and nuclear translocation

21 of Mut T-bet were impaired (Fig. 1C and Fig. S3B). When its DNA-binding activity to consensus

22 T-box regulatory elements (TBRE) was assessed, nuclear proteins from WT-transfected cells

23 bound the WT-TBRE but not the Mut-TBRE, and this specific complex was super-shifted by an 
1 anti-T-bet antibody $(\mathrm{Ab})$ and inhibited by a competitor probe (CP). However, Mut T-bet did not bind WT-TBRE DNA (Fig. 1D). We also tested the ability of WT and Mut T-bet to induce a

3 luciferase transgene under the control of the TBRE or human IFNG proximal promoter (Chen and

4 Prywes, 1999; Janesick et al., 2012; Soutto et al., 2002; Tong et al., 2005a). WT T-bet induced high levels of luciferase activity with WT-TBRE but not with Mut-TBRE. Mut T-bet and the negative controls (T-del and K314R) did not induce luciferase activity (Fig. 1E). Mut T-bet was also LOF for transactivation of the IFNG promoter, whereas the negative control K314R was

8 markedly hypomorphic (Fig. 1F). We investigated the amino-acid substitution responsible for the 9 abolition of transcriptional activity. We tested the effects of the WT and Mut forms of T-bet and 10 of T-bet forms with single-residue substitutions (E156S and M157L), or alanine substitutions

11 (E156A and M157A) on T-bet protein production and transcriptional activity. The loss of E156

12 (E156S and E156A) abolished transcriptional activity, but the production of the T-bet protein was

13 unaffected. By contrast, a loss of methionine residues (M157L and M157A) preserved

14 transcriptional activity but decreased the levels of T-bet protein expression (Fig. S3C and D). T-

15 bet is necessary for the optimal production of IFN- $\gamma$ in NK, ILCs, $\gamma \delta$, and $\mathrm{CD}^{+} \mathrm{T}$ cells in mice

16 and is sufficient for IFN- $\gamma$ production in NK and $\mathrm{CD}^{+} \mathrm{T}$ cells in humans (Chen et al., 2007;

17 Lazarevic et al., 2013; Powell et al., 2012; Szabo et al., 2002; Yu et al., 2006). We investigated

18 the impact of the T-bet mutation on the induction of $I F N G$ expression, by generating CRISPR/Cas9

19 gene-edited human NK-92 cell lines lacking TBX21 (Fig. S4A - D). Upon stimulation with IL-12

$20+$ IL-18, these $T B X 21$ knockout $(\mathrm{KO})$ NK-92 cells displayed a strong impairment of IFN- $\gamma$

21 production (Fig. 1G and Fig. S4E). Following re-introduction of the WT or Mut TBX21-containing

22 plasmid into $T B X 21 \mathrm{KO}$ NK-92 cells, the WT TBX21 rescued IFN- $\gamma$ production by $T B X 21 \mathrm{KO}$

23 cells, whereas the Mut $T B X 21$ did not (Fig. 1H, Fig. S4F and G). Finally, the overexpression of 
1 WT, but not of Mut T-bet increased IFN- $\gamma$ levels to values above those for endogenous production

2 in expanding naïve $\mathrm{CD}^{+}{ }^{\mathrm{T}}$ cells from healthy donors (Fig. 1I and J, Fig. S4H). Thus, Mut T-bet

3 overexpression abolished DNA binding, and the mutant protein had no transactivation activity,

4 failed to induce IFN- $\gamma$ production in an NK cell line or primary $\mathrm{CD}^{+} \mathrm{T}$ cells, and can therefore 5 reasonably be considered a LOF allele.

6

\section{$T B X 21$ variants in the general population are functional}

The TBX21 indel variant in $\mathrm{P}$ was not found in the gnomAD v2.1, Bravo, or Middle Eastern cohort databases, or our in-house database of more than 6,000 exomes, including $>1,000$ individuals of North African origin (Karczewski et al., 2019; Scott et al., 2016; Taliun et al., 2019).

The CADD score of 34 obtained for this allele is well above the MSC of 3.313 (Fig. 1K) (Itan et al., 2016; Kircher et al., 2014; Zhang et al., 2018). The TBX21 gene has a low tolerance of deleterious variations, with a low gene damage index (GDI) score of 3.493 (Itan et al., 2015) and a low residual variation intolerance score (RVIS: -0.74) (Petrovski et al., 2015). Moreover, only three predicted LOF variants (variant: 17:45821662 T / TATCTTTACTTATGCTGTGG, variant: 17:45822565 G / GC, variant: 17:45822322 C/T) were found in the heterozygous state in gnomAD (Karczewski et al., 2019). As their MAFs were $<5 \times 10^{-6}$, homozygosity rates for any of these three variants are well below the prevalence of MSMD (about 1/50,000). In the general population covered by the gnomAD database, seven variants have been identified in the homozygous state: A109G has a low CADD score, below the MSC, whereas H33Q, I339V, Y395C, M331I, R218H, and A29P have CADD scores above the MSC (Fig. 1K and Fig. S5A). The mouse ortholog of H33Q (H32Q) has been shown to be functionally neutral (Tantisira et al., 2004). None of these seven alleles affected transactivation of the WT-TBRE promoter (Fig. 1L and Fig. S5B). 
1 Thus, all the $T B X 21$ variants present in the homozygous state in gnomAD are functionally neutral.

2 In our in-house cohort of $>6,000$ exomes from patients with various infectious phenotypes, $\mathrm{P}$ is

3 the only patient carrying a rare bi-allelic variant at the $T B X 21$ locus. We investigated whether any

4 of the other 28 non-synonymous variants of $T B X 21$ in our in-house database could underlie

5 infections in the heterozygous state, by testing each of them experimentally. None had any

6 functional impact on transcriptional activity (Fig. S5C - E). Therefore, the data for P and his family,

7 our in-house cohort, and the general population suggest that inherited T-bet deficiency, whether

8 complete or partial, is exceedingly rare in the general population $\left(<5.8 \times 10^{-8}\right)$. These findings also

9 suggest that homozygosity for the Mut LOF variant of TBX21 is responsible for MSMD in P.

\section{Homozygosity for the $T B X 21$ mutation underlies complete T-bet deficiency}

We investigated the production and function of endogenous Mut T-bet in T-saimiri virus-

13 transformed $\mathrm{T}$ cells (HVS-T) and primary $\mathrm{CD}^{+} \mathrm{T}$ cells from P. Levels of $T B X 21 \mathrm{mRNA}$ were

14 normal, but endogenous T-bet protein levels were low in P's cells (Fig. 2A and B, Fig. S6A and

15 B). Together with the observation of low levels of Mut T-bet protein on overexpression (Fig. S3),

16 these findings suggest that the TBX21 mutation decreases T-bet protein levels by a post-

17 transcriptional mechanism. T-bet transactivates $I F N G$ and $T N F$ by directly binding to their

18 regulatory promoter or enhancer (Garrett et al., 2007; Kanhere et al., 2012; Soutto et al., 2002;

19 Szabo et al., 2000; Tong et al., 2005a). Levels of spontaneous IFN- $\gamma$ and TNF- $\alpha$ production by P's

20 HVS-T cells were much lower than those for HVS-T cells from healthy donors and heterozygous

21 relatives (Fig. 2 C - F). This defect of cytokine production by $T B X 21$ mutant HVS-T cells was

22 rescued by WT T-bet complementation (Fig. 2G and Fig. S6C). The functional impact of the T-

23 bet mutation was also investigated in primary $\mathrm{CD}^{+} \mathrm{T}$ cells. Upon stimulation with phorbol 12- 
1 myristate 13 -acetate (PMA) and ionomycin (P/I), IFN- $\gamma$ production was almost entirely abolished

2 in P's expanded $\mathrm{T}_{\mathrm{H}} 0$ cell subset and TNF- $\alpha$ production was impaired; the production of both these

3 molecules was rescued by WT T-bet (Fig. 2H and I, Fig. S6D - F). In $T_{H} 1$ conditions, exogenous

4 IL-12 bypassed T-bet and induced moderate IFN- $\gamma$ production by P's cells, but the levels of this

5 cytokine were still $\sim 60-70 \%$ lower than those in healthy controls (Fig. $2 H$ and I). We investigated

6 other T-bet-dependent transcriptional targets, by performing RNA-seq to compare $\mathrm{T}_{\mathrm{H}} 0$ cells from

7 controls, P, and P's cells complemented with WT T-bet after incubation with anti-CD3/28 Ab

8 beads. We found that the transcription of 455 was downregulated and that of 536 genes was

9 upregulated in P's cells (Fig. S7A, Table S5). The complementation of P's cells with WT T-bet

10 reversed the differential expression of 106 of the genes downregulated and 174 of the genes

11 upregulated in P's cells relative to controls (Fig. S7B and C). These targets were enriched in

12 cytokine signaling pathway genes (Fig. 2J). We therefore decided to focus on genes involved in

13 immunological signaling. Only 37 such genes were upregulated, and 33 downregulated in P's cells,

14 but these differences in expression relative to controls were reversed by WT T-bet (Fig. 2K and

15 Fig. S7D - F). Known T-bet-dependent targets, such as IFNG, CCL3 and CXCR3, were

16 downregulated in this patient with T-bet deficiency, whereas IFNGR2 expression was upregulated

17 (Fig. 2L) (Iwata et al., 2017; Jenner et al., 2009). A set of new T-bet target genes was also identified,

18 including CCL1, CCL13, CCL4, CSF2, CXCR5, GZMM, IDO1, IL10, ITGA5, and ITGB5 (Fig.

19 2L). Collectively, our data indicate that the patient had AR complete T-bet deficiency, which

20 affects the expression of a set of T-bet-dependent target genes. 
We analyzed the molecular mechanisms by which T-bet controls transcription.

2 Epigenetically, T-bet, is known to induce a permissive environment for transcription at the IFNG

3 promoter through histone modifications and the suppression of $\mathrm{CpG}$ methylation (Lewis et al.,

4 2007; Miller and Weinmann, 2010; Tong et al., 2005b). However, it remains unknown whether T-

5 bet directly regulates chromatin accessibility in mice or humans. The regulation of $\mathrm{CpG}$

6 methylation at the genome-wide scale by T-bet has never been studied. We performed omni-

7 ATAC-seq analysis and EPIC DNA CpG methylation array analysis with $\mathrm{T}_{\mathrm{H}} 0$ cells derived from

8 P and controls (Corces et al., 2017). In P's cells, a gain of chromatin accessibility was observed at

9 1,787 loci and a loss of chromatin accessibility was observed at 3,689 loci (Fig. 3A and B, Fig.

10 S8A - C). We found that 666 and 1,649 of these loci, respectively, were subject to strict regulation

11 by T-bet, as their gains and losses of chromatin accessibility were reversed by WT T-bet (Fig. 3B,

12 Table S6). The chromatin regions opened out by T-bet were heavily occupied by bound T-bet,

13 whereas those closed up by T-bet did not typically require T-bet binding (Fig. 3C) (Kanhere et al.,

14 2012). An enrichment in T-box and ZBTB7B binding elements was observed in loci displaying an

15 increased chromatin accessibility by T-bet, whereas an enrichment in Forkhead box elements was

16 observed at loci at which chromatin accessibility was decreased by T-bet (Fig. 3D - F). The

17 chromatin accessibility of 192 immunological genes, including $I L 23 R$ and IRF8, two known

18 MSMD-causing genes (Hambleton et al., 2011; Martínez-Barricarte et al., 2018; Salem et al.,

19 2014), was increased by T-bet, whereas that of 75 immunological genes was decreased by T-bet

20 (Fig. 3G, Fig. S8 and 9). Three known T-bet-dependent targets, IFNG, TNF and CXCR3, were

21 among the top hits for the differentially regulated loci. The transcription start sites (TSS) of IFNG

22 and $T N F$, the proximal promoter of $I F N G$, and the enhancers of $C X C R 3$ were inaccessible in T-

23 bet deficient cells, and this inaccessibility was rescued by WT T-bet (Fig. 3H - J). The EPIC DNA 
1 CpG methylation array analysis identified $644,236 \mathrm{CpG}$ sites that were differentially regulated

2 (Table S7). Three CpG loci within IFNG were hypermethylated in conditions of T-bet deficiency,

3 whereas their methylation was reduced to levels similar to those in controls on complementation

4 with WT T-bet (Fig. 3K and L). NR5A2, TIMD4, ATXN2, ZAK, SLAMF8, TBKBP1, CD247,

$5 H D A C 4$ and several other genes were also regulated in a similar manner (Fig. 3K). Interestingly,

6 the methylation of six CpG loci within ENTPD1 not previously linked to T-bet also increased in a

7 T-bet-dependent manner (Fig. 3K and $\mathbf{L}$ ). By contrast, IL10 was a top target for which CpG

8 methylation was drastically reduced in T-bet deficiency but rescued by WT T-bet (Fig. 3K and

9 M). Taken together, these results demonstrate that T-bet orchestrates the expression of target genes

10 by modulating both their chromatin accessibility and $\mathrm{CpG}$ methylation. Genome-wide omni-

11 ATAC-seq and CpG methylation array analyses identified new epigenetic targets of T-bet (Table

12 S6 and S7). They also showed that chromatin accessibility at IFNG was increased by T-bet at both

13 the TSS and promoter sites, whereas the CpG methylation of IFNG was dampened by T-bet at 14 three different positions.

18 blood counts for fresh samples from P fresh samples showed that the numbers of lymphocytes,

19 neutrophils, and monocytes were normal. We studied the PBMC subsets of P after the patient had

20 been cured of mycobacterial disease, by mass cytometry (cytometry by time-of-flight, CyTOF)

21 studies of 38 markers and comparisons with P's parents, healthy donors, and patients with IL-

$2212 \mathrm{R} \beta 1$ deficiency, the most common etiology of MSMD, as controls. The frequencies of 23 plasmacytoid DCs (pDCs) and conventional DC 1 and 2 (cDC1 and cDC2) were not affected by 
1 human T-bet deficiency (Fig. S10). All major myeloid lineages were normal in P. We therefore

2 focused on the development of lymphoid lineages. Total NK cells (defined as $\mathrm{Lin}^{-\mathrm{CD}} 7^{+} \mathrm{CD} 16^{+}$or

$3 \mathrm{CD}^{+}$) were present in normal numbers in P. However, CD16 ${ }^{+}$and $\mathrm{CD}^{\text {bright }} \mathrm{NK}$ cells levels

4 were $\sim 25$ - and $\sim 15$-fold lower, respectively, in P than in the controls (Fig. 4A - C). Moreover, P

5 had an abnormally high frequency of CD56-CD127- NK cells (Fig. S11); this NK cell subset has

6 low levels of cytotoxicity and is rare in healthy and normal individuals (Björkström et al., 2010).

7 The frequencies of ILC precursor (ILCP) and ILC2 in P were similar to those in healthy donors

8 and IL-12R $\beta 1$-deficient patients (Fig. S12). In stringent analyses, ILC1 and ILC3 are too rare for

9 quantification in human peripheral blood (Lim et al., 2017). Overall, human T-bet is required for

10 the correct development or maturation of NK cells, but not monocytes, DCs, ILC2 or ILCP.

\section{Diminished iNKT, MAIT, and $V \delta 2^{+} \gamma \delta$ T-cell lineages in T-bet deficiency}

14 receptor (TCR) diversity than conventional, "purely" adaptive $\alpha \beta$ T cells (Chien et al., 2014;

15 Crosby and Kronenberg, 2018; Godfrey et al., 2019). iNKT cells constitute a group of T cells with

16 invariant TCRs combining properties from both T cells and NK cells (Crosby and Kronenberg,

17 2018). The iNKT cells of $\mathrm{P}$ were barely detectable (present at levels $\sim 200$-fold lower than in

18 controls) (Fig. 4D, Fig. S13A and B). MAIT cells express invariant Va7.2-Ja33 TCR $\alpha$ restricted

19 by a monomorphic class I-related MHC molecule, along with ligands derived from vitamin B

20 synthesis (Kjer-Nielsen et al., 2012; Xiao and Cai, 2017). P also had a lower frequency of MAIT

21 cells than controls ( $\sim 15$-fold) (Fig. 4E and Fig. S13C). Total $\gamma \delta$ T-cell frequency in P was normal

22 (Fig. S13D). However, the frequency of the $\mathrm{V} \delta 2^{+}$subset, a group of $\gamma \delta \mathrm{T}$ cells that recognize

23 phosphoantigen (pAgs) (Gu et al., 2018; Harly et al., 2012; Vavassori et al., 2013), was low ( 8- 
1 fold lower than control levels) in $\mathrm{P}$, whereas the $\mathrm{V} \delta 1^{+}$subset of $\gamma \delta \mathrm{T}$ cells was normal (Fig. 4F,

2 Fig. S13E and F). Mild abnormalities of B-lymphocyte development and antibody production

3 unrelated to the patient's mycobacterial disease were observed and will be reported in a separate

4 study (Yang $\mathrm{R}$, in preparation). $\mathrm{CD}^{+}$and $\mathrm{CD}^{+} \alpha \beta \mathrm{T}$ cells were the two most prevalent blood

5 lineages of adaptive lymphocytes expressing a highly diverse $\alpha \beta$ TCR repertoire. Antigen-driven

$6 \mathrm{CD}^{+} \mathrm{T}$-cell effector responses and the optimal induction of memory $\mathrm{CD}^{+} \mathrm{T}$ cells in mice are

7 controlled by T-bet (Bettelli et al., 2004; Juedes et al., 2004; Sullivan et al., 2003). In the T-bet-

8 deficient patient, total $\mathrm{CD}^{+} \mathrm{T}$ cells and the composition of naïve, central memory, effector

9 memory and $\mathrm{T}_{\text {EMRA }}$ cells were normal (Fig. S13G). We further investigated $\mathrm{CD}^{+} \mathrm{T}$ cells in an

10 unbiased manner, by automatic viSNE clustering with a panel of surface markers, including

11 chemokine receptors (Amir el et al., 2013). We found no apparent difference between the memory

$12 \mathrm{CD}^{+} \mathrm{T}$ cells of $\mathrm{P}$ and controls. However, a small subset of naïve $\mathrm{CD}^{+} \mathrm{T}$ cells

13 (CD45RA ${ }^{+} \mathrm{CD} 38^{\text {int }} \mathrm{CXCR} 3^{\text {int }} \mathrm{CCR} 6^{-} \mathrm{CCR} 5^{-} \mathrm{CD} 27^{\text {high }} \mathrm{CD} 127^{\text {high }}$ ) was absent from P (Fig. S13H).

14 Thus, the development of iNKT, MAIT cells, $\mathrm{V} \delta 2^{+} \gamma \delta \mathrm{T}$ cells, and a small subset of naïve $\mathrm{CD} 8^{+} \mathrm{T}$

15 cells is impaired in T-bet deficiency.

\section{Selective depletion of $\mathrm{CCR6}^{-} \mathrm{T}_{\mathbf{H}} 1$ in $\mathrm{CD4}^{+} \mathrm{T}$ cells in $\mathrm{T}$-bet deficiency}

Both $\mathrm{P}$ and his heterozygous parents had normal distributions of naïve and memory CD4 ${ }^{+}$

19 T cells (Fig. S14A). We further analyzed individual $\mathrm{CD}^{+}{ }^{+}$T-cell subsets, by viSNE clustering on

20 antigen-experienced cells in particular (Amir el et al., 2013). Several memory CD4 ${ }^{+}$T-cell $^{2}$

21 populations typically present in healthy donors were missing in P. Indeed, most of the CCR $5^{+}$cells

22 (subset 1 ) and $\mathrm{CXCR}^{+}$cells (subsets 3 and 4), corresponding to $\mathrm{T}_{\mathrm{H}} 1$ cells in humans (Groom and

23 Luster, 2011; Loetscher et al., 1998; Sallusto et al., 1998), were missing in P (Fig. 4G and Fig. 
1 S14B). A subset of $\mathrm{CXCR}^{\text {high }}$ memory $\mathrm{CD}^{+} \mathrm{T}$ cells $\quad(\mathrm{CXCR} 3$ subset 2 -

2 CXCR3 ${ }^{\text {high }} \mathrm{CD} 27^{\text {low }} \mathrm{CD} 127^{\text {low }} \mathrm{CD} 38^{\text {int }}$ ) was, however, preserved (Fig. 4G). A cluster of

$3 \mathrm{CD}_{2} 27^{+} \mathrm{CD} 27^{+} \mathrm{CD} 25^{+} \mathrm{CCR} 7^{+} \mathrm{CD} 161^{+}$cells (subset 5) was also missing (Fig. 4G). The frequency

4 of classic $\mathrm{CXCR}^{+} \mathrm{CCR}^{-} \mathrm{T}_{\mathrm{H}} 1$ cells was lower than that in controls (about nine-fold lower),

5 whereas the frequency of $\mathrm{CXCR} 3{ }^{+} \mathrm{CCR} 6{ }^{+}$non-classic $\mathrm{T}_{\mathrm{H}} 1 *$ cells, which are known to be mostly

6 mycobacterium-specific, was unaffected (Fig. $4 \mathbf{H}$ and $\mathbf{I})$. The frequencies of human $\mathrm{T}_{\mathrm{H}} 2, \mathrm{~T}_{\mathrm{H}} 17$,

7 and follicular helper $\left(\mathrm{T}_{\mathrm{FH}}\right)$ cells in peripheral blood were normal (Fig. S14C - E). However, the

8 CXCR3 $^{+} \mathrm{T}_{\mathrm{FH}}$ cells, a group of $\mathrm{T}_{\mathrm{H}} 1$-biased $\mathrm{T}_{\mathrm{FH}}$ cells that produce IFN- $\gamma$ together with IL-21 in

9 germinal centers (Velu et al., 2016; Zhang et al., 2019a), was diminished in P (Fig. S14E).

$10 \mathrm{CXCR}^{+}$regulatory $\mathrm{T}$ cells (Tregs), a group of $\mathrm{T}_{\mathrm{H}} 1$-skewed Tregs (Koch et al., 2009; Levine et

11 al., 2017; Tan et al., 2016), and CCR5 ${ }^{+}$Tregs were also present at abnormally low levels, but the

12 level of total Tregs was normal (Fig. S14F and G). Thus, human T-bet deficiency selectively

13 impairs the development of the classic $\mathrm{CCR}^{-} \mathrm{T}_{\mathrm{H}} 1, \mathrm{CXCR}^{+} \mathrm{T}_{\mathrm{FH}}$, and $\mathrm{CXCR}^{+}$or $\mathrm{CCR}^{+} \mathrm{Treg}^{-}$

$14 \mathrm{CD}^{+} \mathrm{T}$-cell subsets, but has no effect on the $\mathrm{T}_{\mathrm{FH}}, \mathrm{T}_{\mathrm{H}} 2, \mathrm{~T}_{\mathrm{H}} 17, \mathrm{CCR}^{+} \mathrm{T}_{\mathrm{H}} 1^{*}$, and total Treg subsets,

15 as shown by CyTOF and flow cytometry.

\section{Single-cell transcriptomic profile in vivo is altered by T-bet deficiency}

18 We investigated the development and phenotype of leukocyte subsets in the patient further,

19 by performing single-cell RNA-seq (scRNA-seq) with PBMCs from $\mathrm{P}$ and his father. The

20 clustering of the various immune subsets yielded eight distinct major subsets: NK cells, pDCs,

21 monocytes, B cells, $\mathrm{CD}^{+}$cytotoxic $\mathrm{T}$ lymphocytes (CTLs), $\mathrm{CD} 8^{+}$naïve, $\mathrm{CD} 4^{+}$naïve and $\mathrm{CD} 4^{+}$

22 effector/memory $\mathrm{T}\left(\mathrm{T}_{\mathrm{EM}}\right)$ cells (Becht et al., 2019). Consistent with the CyTOF results, normal

23 frequencies of $\mathrm{pDC}, \mathrm{CTL}, \mathrm{CD}^{+}$naïve, $\mathrm{T}_{\mathrm{EM}}$, and a low frequency of $\mathrm{NK}$ cells were obtained with 
1 scRNA-seq (Fig. S15A). We investigated the transcriptomic changes at single-cell level associated

2 with T-bet deficiency, by filtering to select all genes with expression detected in $>5 \%$ of cells in

3 at least one cluster, with at least a four-fold change in expression. We identified 34 genes as

4 differentially regulated in T-bet-deficient cells relative to a heterozygous control. As for our RNA-

5 seq data, some targets, including $C X C R 3$ in $\mathrm{T}_{\mathrm{EM}}, \mathrm{CD} 8^{+} \mathrm{CTL}$, and $\mathrm{NK}$ cells, IRF8 in NK cells, and

$6 C C L 4$ and CCL3 in all cell types, before which expression was known to be dependent on T-bet,

7 were downregulated in T-bet-deficient cells (Fig. 4J and Fig. S15B). The expression of XCL1,

8 STAT4, SOX4, LMNA and ANXA1 was also impaired in at least one subset of T-bet-deficient cells

9 (Fig. 4J and Fig. S15B). In humans and mice, XCL1, STAT4, SOX4, LMNA and ANXA1 are

10 known to be involved in $\mathrm{T}_{\mathrm{H}} 1$ immunity (Dorner et al., 2002, 2003, 2004; Gavins and Hickey, 2012;

11 Kroczek and Henn, 2012; Nishikomori et al., 2002; Thieu et al., 2008; Toribio-Fernández et al.,

12 2018; Yoshitomi et al., 2018). NKG7 is involved in the initiation of human $\mathrm{T}_{\mathrm{H}} 1$ commitment and

13 its genetic locus is tightly occupied by T-bet (Jenner et al., 2009; Kanhere et al., 2012; Lund et al.,

14 2005). The expression of $N K G 7$ in $\mathrm{CD}^{+}, \mathrm{CD}^{+}$and $\mathrm{B}$ cells was dependent on functional T-bet,

15 whereas PRM1 was downregulated in $\mathrm{CD}^{+} \mathrm{T}$ and $\mathrm{CD} 8^{+} \mathrm{CTL}$ cells from $\mathrm{P}$ (Fig. 4J). The $I F N G$

16 gene was weakly expressed across lymphocyte populations, as shown by scRNAseq, and its

17 expression did not seem to be dependent on T-bet in basal conditions (data not shown). In addition,

18 the expression of several genes not previously linked to T-bet was also altered in at least one cell

19 subset in P (Fig. 4J). Thus, in addition to IRF8, CXCR3, NKG7, CCL3 and CCL4, the expression

20 of which was weak in at least one immune subset from this patient with human T-bet deficiency,

21 consistent with the findings of RNA-seq and omni-ATAC-seq, T-bet is also important for the

22 expression of a set of previously unknown target genes in immune subsets (Fig. 4J). 


\section{Impaired IFN- $\gamma$ production by NK, MAIT, $V \delta 2^{+} \gamma \delta \mathrm{T}$, and $\mathrm{CD8}^{+} \mathrm{T}$ lymphocytes}

Human IFN- $\gamma$ is essential for antimycobacterial immunity, as all 30 known genetic

3 etiologies of MSMD affect IFN- $\gamma$-dependent immunity. The in vivo development of NK, iNKT,

4 MAIT, $V \delta 2^{+} \gamma \delta \mathrm{T}$, and classic $\mathrm{T}_{\mathrm{H}} 1$ cells was found to be impaired in $\mathrm{P}$, but it remained possible

5 that the IFN- $\gamma$ production capacity of the remaining lymphocytes could compensate, thereby

6 contributing to antimycobacterial immunity. We assessed the potential of P's NK cells to respond

7 to ex vivo stimulation with IL-12, IL-15 and IL-18. When stimulated, total NK cells from P

8 displayed impaired degranulation, with low levels of CD107a expression, and almost no IFN- $\gamma$

9 production (Fig. 5A and B, Fig. S16A-C). However, intracellular perforin and granzyme B levels

10 in NK cells were unaffected by T-bet deficiency (Fig. S16D and E). The frequency of IFN- $\gamma-$

11 producing total lymphocytes was also low in $\mathrm{P}(\sim 18$-fold lower than in controls), whereas the

12 frequency of TNF- $\alpha$-producing cells was only slightly lower than in the controls ( 2.5 -fold lower),

13 in response to P/I stimulation ex vivo (Fig. 5C - E). By contrast, no detectable IFN- $\gamma$-producing

14 iNKT cells were detected in P or controls due to their very low frequency in peripheral blood.

15 MAIT cells were present at a lower ( $\sim 14$-fold lower than controls) frequency in vivo in $\mathrm{P}$, and

16 these cells presented impaired production of IFN- $\gamma(\sim 9$-fold lower than control levels) and TNF- $\alpha$

17 ( $\sim 3$ fold-fold lower) ex vivo (Fig. 5F and G, Fig. S16F). Similarly, IFN- $\gamma$-producing $V \delta 2^{+} \gamma \delta \mathrm{T}$

18 cells were barely detectable ( $\sim 17$-fold less frequent than in controls) whereas the frequency of

19 TNF- $\alpha$-producing $\mathrm{V} \delta 2^{+} \gamma \delta \mathrm{T}$ cells was only slightly low ( $\sim 3$-fold lower than control levels) ex vivo

20 (Fig. 5H and I, Fig. S16G). By contrast, we observed no difference in IFN- $\gamma$ and TNF- $\alpha$

21 production by the cells of the $\mathrm{V} \delta 2^{-} \gamma \delta \mathrm{T}$ subset between $\mathrm{P}$ and controls (Fig. 5J and K, Fig. S16H).

$22 \mathrm{CD}^{+} \mathrm{T}$ cells secrete substantial amounts of IFN- $\gamma$ upon microbial challenge (Wilson and

23 Schoenborn, 2007). The frequency of $\mathrm{CD}^{+} \mathrm{T}$ cells producing IFN- $\gamma$ in response to $\mathrm{P} / \mathrm{I}$ was low in 
$1 \mathrm{P}$ (about 28-fold lower than in controls), whereas the frequency of TNF- $\alpha$-producing $\mathrm{CD}^{+} \mathrm{T}$ cells

2 was unaffected (Fig. 5L and M, Fig. S16I). Among the remaining circulating lymphocytes in the

3 patient, NK, MAIT, $\mathrm{V} \delta 2^{+} \gamma \delta \mathrm{T}$ cells, and $\mathrm{CD} 8^{+} \mathrm{T}$ were equally defective for the production of

4 IFN- $\gamma$ ex vivo in response to IL-12, IL-15, IL-18 or P/I stimulation whereas V $\delta 2^{-} \gamma \delta$ T cells were 5 not.

6

\section{Selective impairment of IFN- $\gamma$ production by $\mathbf{T}_{H}$ cells in $\mathbf{T}$-bet deficiency}

T-bet was first discovered and has been most extensively studied in $\mathrm{CD}^{+} \mathrm{T}$ cells in the context of mouse $T_{H} 1$ cells (Szabo et al., 2000, 2002). This discover, together with that of GATA3 (Zheng and Flavell, 1997), revealed the molecular determinism of $\mathrm{T}_{\mathrm{H}} 1 / \mathrm{T}_{\mathrm{H}} 2 \mathrm{CD}^{+} \mathrm{T}$ cell differentiation and paved the way for an understanding of $\mathrm{T}_{\mathrm{H}} 17$, iTreg, $\mathrm{T}_{\mathrm{H}} 22, \mathrm{~T}_{\mathrm{FH}}$, and $\mathrm{T}_{\mathrm{H}} 9$ cell lineage determination (Zhu et al., 2010). We therefore investigated the impact of T-bet deficiency in primary $\mathrm{CD}^{+} \mathrm{T}$ cells. IFN- $\gamma$ production by memory $\mathrm{CD}^{+} \mathrm{T}$ cells was impaired by $\mathrm{T}$-bet deficiency (Fig. 5N and $\mathbf{O}$ ). Another $\mathrm{T}_{\mathrm{H}} 1$ cytokine, TNF- $\alpha$, was also produced in smaller amounts by memory $\mathrm{CD}^{+} \mathrm{T}$ cells from $\mathrm{P}$ than by those of most of the healthy controls (Fig. 5P and Q). The memory $\mathrm{CD}^{+} \mathrm{T}$ cells of $\mathrm{P}$ produced larger amounts of the $\mathrm{T}_{\mathrm{H}} 17$ effector cytokines IL-22 and IL-17A than those from healthy donors (Fig. 5R and S, Fig. S17A). Unlike previous studies (Gokmen et al., 2013; Zhang et al., 2019b), we found that T-bet deficiency had no effect on IL-9 production ex vivo (Fig. S17B and C). Surprisingly, ex vivo $\mathrm{T}_{\mathrm{H}} 2$ cytokines from memory $\mathrm{CD}^{+} \mathrm{T}$ cells were not affected by human T-bet deficiency (Fig. S17E - G). P's memory CD4 ${ }^{+}$cells produced less IL-21 ex vivo than the memory $\mathrm{CD}^{+}$cells of most of the controls (Fig. S17H). We then investigated the role of $\mathrm{T}$-bet in human $\mathrm{T}_{\mathrm{H}}$ cell differentiation in vitro. Naïve $\mathrm{CD} 4^{+} \mathrm{T}$ cells from $\mathrm{P}$ or healthy donors were allowed to differentiated in $\mathrm{T}_{\mathrm{H}} 0, \mathrm{~T}_{\mathrm{H}} 1, \mathrm{~T}_{\mathrm{H}} 2, \mathrm{~T}_{\mathrm{H}} 9$, or $\mathrm{T}_{\mathrm{H}} 17$ conditions. 
1 The induction of IFN- $\gamma$ production in naïve $\mathrm{CD}^{+} \mathrm{T}$ cells was abolished by T-bet deficiency under

$2 \mathrm{~T}_{\mathrm{H}} 1$ conditions (Fig. 5 T and $\left.\mathbf{U}\right)$. Similarly, T-bet-deficient naïve CD4 ${ }^{+} \mathrm{T}$ cells produced less TNF-

$3 \alpha$ than the corresponding cells from most controls (Fig. $5 \mathbf{V}$ and $\mathbf{W}$ ). Furthermore, the induction of

4 IL-9 in various conditions in vitro was weaker in naïve $\mathrm{CD}^{+} \mathrm{T}$ cells from $\mathrm{P}$ than in the

5 corresponding cells from most controls (Fig. S17I and $\mathbf{J})$. In vitro-induced $\mathrm{T}_{\mathrm{H}} 2$ cells from $\mathrm{P}$

6 produced more IL-10, but not IL-13, than control cells (Fig. S17K and L). Even memory CD4 ${ }^{+}$T

7 cells from $\mathrm{P}$ displayed impaired IFN- $\gamma$ and $\mathrm{TNF}-\alpha$ production under $\mathrm{T}_{\mathrm{H}} 1$ polarizing conditions

8 (Fig. 5X). Thus, AR T-bet deficiency leads not only to defective IFN- $\gamma$ and TNF- $\alpha$ production $e x$

9 vivo and in vitro, but also to a moderate upregulation of the production of IL-17A and IL-22, two

10 cytokines characteristic of $\mathrm{T}_{\mathrm{H}} 17$ cells (Lazarevic et al., 2011).

\section{Poor cellular response to BCG infection in vitro in T-bet deficiency}

14 leukocyte subsets producing the largest amounts of IFN- $\gamma$ in a T-bet-dependent manner during

15 acute BCG infection in vitro. The infection of PBMCs with BCG induced IFN- $\gamma$ production, which

16 was further increased by stimulation with exogenous IL-12 (Fig. 6A). PBMCs from P had low

17 levels of IFN- $\gamma$ production but normal levels of IL-6 and TNF- $\alpha$ production, and high levels of IL-

185 and IL-13 production in response to BCG infection (Fig. 6A, Fig. S18). Almost all the IFN- $\gamma-$

19 producing cells had high levels of T-bet expression (Fig. S19). Thus, T-bet ${ }^{+}$IFN- $\gamma^{+}$double-

20 positive cells were the major antimycobacterial cells, with a function potentially dependent on $\mathrm{T}$ -

21 bet. However, T-bet ${ }^{+}$IFN- $\gamma^{+}$cells were low during acute infection in P (Fig. 6B). Among the T-

$22 \mathrm{bet}^{+} \mathrm{IFN}-\gamma^{+}$cells of healthy donors, $\mathrm{CD} 56^{+} \mathrm{NK}, \mathrm{V} \alpha 7.2^{+} \mathrm{MAIT}, \mathrm{V} \delta 2^{+} \gamma \delta \mathrm{T}$, and $\mathrm{CD} 4^{+} \mathrm{T}$ cells were

23 the dominant responders in the absence of additional cytokine, while $\mathrm{V} \delta 2^{-} \gamma \delta \mathrm{T}$, iNKT and $\mathrm{CD}^{+}$ 
1 T cells represented the minority (Fig. 6C and D, Fig. S20A). However, these subsets of T-bet ${ }^{+}$

2 IFN- $\gamma^{+}$cells were almost entirely depleted from P's PBMCs following BCG infection (Fig. 6D

3 and Fig. S20B). We then investigated each leukocyte subset separately. Fewer than $1 \%$ of V $\delta 2^{-}$

$4 \gamma \delta \mathrm{T}$ cells, B cells, or $\mathrm{CD}^{+} \mathrm{T}$ cells became $\mathrm{T}^{- \text {bet }^{+}} \mathrm{IFN}^{-} \gamma^{+}$during BCG infection (Fig. 6E).

5 However, $\sim 4-7 \%$ of NK cells, iNKT, MAIT cells, and up to $\sim 15 \%$ of $\mathrm{V} \delta 2^{+} \gamma \delta \mathrm{T}$ cells from healthy

6 donors, but not those from P, became T-bet ${ }^{+}$IFN- $\gamma^{+}$in response to BCG infection, and the

7 frequency of these cells was further increased by exogenous IL-12 (Fig. 6E). Thus, the IFN- $\gamma$

8 production controlled by $\mathrm{T}$-bet during acute BCG infection in vitro takes place mostly in NK,

$9 \mathrm{MAIT}, \mathrm{V} \delta 2^{+} \gamma \delta \mathrm{T}$ and $\mathrm{CD}^{+} \mathrm{T}$ cells, but not in $\mathrm{CD}^{+} \mathrm{T}$ cells. These experimental findings in vitro

10 do not exclude a contribution of other subsets in vivo. Thus, the NK, iNKT, MAIT, and $\mathrm{V} \delta 2^{+} \gamma \delta \mathrm{T}$

11 cells from healthy donors responded robustly to acute BCG infection in vitro, but these subsets

12 were absent or functionally deficient in the patient with human T-bet deficiency.

\section{Defective prolonged anti-BCG immunity mediated by $V \delta 2^{+} \gamma \delta \mathrm{T}$ cells}

The stimulation of PBMC in vitro with live BCG involves both antigens specifically

16 recognized by mycobacterium-specific cognate $\alpha \beta$ and $\gamma \delta \mathrm{T}$ cells and many other stimuli. BCG

17 infection in vitro mimics acute infection in vivo, but may not be robust enough for investigations

18 of the antigen-specific adaptive immune response, particularly as concerns prolonged adaptive

19 immunity. We therefore studied $\mathrm{V} \delta 2^{+} \gamma \delta \mathrm{T}$ cells and $\mathrm{CD}^{+} \alpha \beta \mathrm{T}$ cells, two adaptive immune

20 lymphocyte subsets that produced significant amounts of IFN- $\gamma$ during BCG infection in vitro and

21 are known to function in an antigen-specific manner. In PBMCs from healthy donors, $\sim 15 \%$ of the

$22 \mathrm{~V} \delta 2^{+} \gamma \delta \mathrm{T}$ cells became T-bet ${ }^{+} \mathrm{IFN}-\gamma^{+}$during BCG infection (Fig. 6E). V $\delta 2^{+} \gamma \delta \mathrm{T}$ cells, a major

23 subset of $\gamma \delta \mathrm{T}$ cells recognizing phosphoantigen (pAg) derived from microbial sources (Gu et al., 
1 2018; Harly et al., 2012; Vavassori et al., 2013), are also known to play an essential role in the

2 recall response to mycobacterial re-infection in humans and non-human primates (Chen, 2005;

3 Shen et al., 2002). They proliferate vigorously in response to mycobacterial infection in vivo and

4 can expand robustly in response to pAg-rich-lysates of mycobacterial species in vitro (Hoft et al.,

5 1998; Modlin et al., 1989; Panchamoorthy et al., 1991; Parker et al., 1990; Tsukaguchi et al., 1995).

6 We investigated whether $\mathrm{V} \delta 2^{+} \gamma \delta \mathrm{T}$ cells were functionally affected in the patient with $\mathrm{T}$-bet

7 deficiency, as these cells represented a small, but important proportion $(\sim 0.2 \%)$ of P's peripheral

8 lymphocytes. The populations of $\mathrm{V} \delta 2^{+} \mathrm{T}$ cells from all controls and relatives of $\mathrm{P}$ expanded

9 vigorously following prolonged stimulation with BCG lysates. By contrast, no such expansion was

10 observed for T-bet-deficient $\mathrm{V} \delta 2^{+} \mathrm{T}$ cells (Fig. 6F and G, Fig. S21A and B). After two weeks of

11 expansion, the levels of IFN- $\gamma$ production by T-bet-deficient cells were lower than those for

12 healthy control cells (Fig. S21C).

\section{Redundant role of T-bet in IFN- $\gamma$ production by BCG-specific cognate $T_{H} 1^{*}$ cells}

It remains unclear whether the prolonged adaptive immunity to mycobacteria elicited by

16 memory $\mathrm{CD}^{+} \mathrm{T}$ cells is dependent on $\mathrm{T}$-bet. We addressed this issue by screening antigen-reactive

$17 \mathrm{~T}$ cell libraries established from $\mathrm{CD}^{+} \mathrm{CCR}^{-}$(containing classic $\mathrm{T}_{\mathrm{H}} 1$ cells) and $\mathrm{CD}^{+} \mathrm{CCR} 6^{+}$

18 (containing $\mathrm{T}_{\mathrm{H}} 1^{*}$ Mycobacterium-responsive cells) memory subsets (Geiger et al., 2009).

19 Consistent with our in vivo findings, the $\mathrm{T}$ cells in the $\mathrm{CD}^{+} \mathrm{CCR} 6^{-}$and $\mathrm{CD} 4^{+} \mathrm{CCR} 6^{+}$libraries had

20 low levels of CXCR3 or IFN- $\gamma\left(\right.$ Fig. S21D - G). P's CD4 ${ }^{+} \mathrm{CCR} 6^{+}$T-cell library responded robustly

21 to $\mathrm{BCG}$, tetanus toxoid and C. albicans, and his $\mathrm{CD}^{+} \mathrm{CCR}^{-} \mathrm{T}$-cell library responded normally to

22 influenza virus, cytomegalovirus (CMV), and EBV (Fig. S21H - N). Despite intact proliferation,

23 IFN- $\gamma$ production from T-bet-deficient $\mathrm{T}$ cells responding to influenza virus, EBV, tetanus toxoid, 
1 and C. albicans was weak (Fig. S21O -S). However, P's CCR6 $6^{+}$T cells, consisting almost entirely

2 of Mycobacterium-specific memory $\mathrm{T}_{\mathrm{H}} 1 *$ cells, proliferated robustly in response to BCG peptides.

3 Moreover, their IFN- $\gamma$ production was normal (Acosta-Rodriguez et al., 2007; Becattini et al.,

4 2015), and their levels of IL-10 production were slightly higher (Fig. 6H and Fig. S21T). The

5 normal levels of IFN- $\gamma$ production could not be attributed to cells with a revertant genotype, as

6 reported in other T-cell primary immunodeficiency diseases (PIDs), because the IFN- $\gamma^{+}$BCG-

7 specific $\mathrm{T}$-cell clones still carried the $T B X 21$ indel variant (data not shown) (Davis et al., 2008;

8 Revy et al., 2019). Thus, the prolonged immunity to BCG infection mediated by $\mathrm{V} \delta 2^{+} \gamma \delta \mathrm{T}$ and

9 memory $\mathrm{CD}^{+} \mathrm{T}$ cells was divergently controlled by $\mathrm{T}$-bet, as $\mathrm{T}$-bet was required for the generation

10 of long-term immunity due to $\mathrm{V} \delta 2^{+} \gamma \delta \mathrm{T}$ cells, but redundant for IFN- $\gamma$ production by BCG-

11 specific cognate $\mathrm{T}_{\mathrm{H}} 1^{*}$ cells. 


\section{Discussion}

We report the identification and study of a patient with MSMD due to inherited, complete

3 T-bet deficiency. Key observations made in T-bet-deficient mice were validated in this human

4 patient with T-bet deficiency: 1) the development of $\mathrm{T}_{\mathrm{H}} 1$ cells and their production of effector

5 cytokines, including IFN- $\gamma$ in particular, requires T-bet (Szabo et al., 2000, 2002); 2) the

6 development of NK and iNKT cells is dependent on T-bet (Townsend et al., 2004) (Table S8); 3)

7 the regulation of T-bet-dependent targets, including $C X C R 3, T N F$ and $I F N G$, involves both direct

8 transactivation and epigenetic modulation (Miller and Weinmann, 2010). Accordingly, T-bet-

9 deficient mice are highly vulnerable to mycobacteria, including Mycobacterium tuberculosis and

10 Mycobacterium avium (Matsuyama et al., 2014; Sullivan et al., 2005), like mice deficient for other

11 genes that govern IFN- $\gamma$ immunity (Casanova, 1999). By contrast, despite the requirement of T-

12 bet for immunity against a broad spectrum of pathogens following experimental inoculation in

13 mice, the only apparent infectious phenotype of the T-bet-deficient patient is MSMD (Table S9).

14 Our study provides compelling evidence that inherited T-bet deficiency is a genetic etiology of

15 MSMD due to the disruption of IFN- $\gamma$ immunity (Casanova et al., 2014). This experiment of nature

16 suggests that $\mathrm{T}$-bet is required for protective immunity to intramacrophagic mycobacteria but

17 largely redundant for immunity to most intracellular pathogens, including viruses in particular.

18 This is at odds with findings in mice, but consistent with other genetic etiologies of MSMD, all of

19 which are inborn errors of IFN- $\gamma$ immunity (Boisson-Dupuis et al., 2018; Martínez-Barricarte et

20 al., 2018; Rosain et al., 2019) (Table S9). Our observation further suggests that the functions of

21 T-bet unrelated to IFN- $\gamma$ are redundant in humans. The identification of additional T-bet-deficient

22 patients is required to draw firm conclusions. Yet, it is striking that humans genetically deprived 
1 of key immunological molecules, other than T-bet or IFN- $\gamma$, often show a much greater redundancy

2 than the corresponding mutant mice (Casanova and Abel, 2004, 2018).

3 Our study also reveals unexpected immunological abnormalities not documented in T-bet-

4 deficient mice that also contribute to the development of MSMD: 1) T-bet was required for the

5 optimal development of two innate-like adaptive lineages of immune cells, MAIT and V $\delta 2^{+} \gamma \delta \mathrm{T}$ cells; 2) T-bet was also required for the production of IFN- $\gamma$ by the few cells from these two subsets

7 that were able to develop. Unexpectedly, IFN- $\gamma$ production by cognate purely adaptive Mycobacterium-specific $\mathrm{T}_{\mathrm{H}} 1 * \mathrm{CD}^{+} \mathrm{T}$ cells was unaffected by $\mathrm{T}$-bet deficiency. Taken together,

9 impaired IFN- $\gamma$ production by NK and iNKT cells, as in mice, and by MAIT and $\mathrm{V} \delta 2^{+} \gamma \delta \mathrm{T}$ cells,

10 as shown here, accounts for MSMD in this patient with T-bet deficiency, despite normal $\mathrm{T}_{\mathrm{H}} 1$ *

11 development and function. By contrast, inborn errors of immunity that disrupt IFN- $\gamma$ production

12 by selective depletion of $\mathrm{NK}$, iNKT, $\mathrm{CD}^{+}$, or $\mathrm{CD}^{+} \alpha \beta \mathrm{T}$ cells do not underlie mycobacterial

13 disease, because of the compensation provided by other subsets (Table S2). Conversely, the loss

14 of all T-cell subsets in severe combined immunodeficiency does result in predisposition to

15 mycobacterial disease. Interestingly, a different combination of deficits accounts for MSMD in

16 patients with ROR $\gamma \mathrm{T}$ deficiency, who lack iNKT and MAIT cells and whose $\gamma \delta \mathrm{T}$ and $\mathrm{T}_{\mathrm{H}} 1 *$ cells

17 do not produce IFN- $\gamma$, while their NK cells are unable to compensate (Okada et al., 2015). T-bet

18 and ROR $\gamma \mathrm{T}$ deficiencies are characterized by iNKT, MAIT, and $\gamma \delta \mathrm{T}$-cell deficiencies, whereas

19 an NK deficit is observed only in T-bet deficiency and a deficit of $\mathrm{T}_{\mathrm{H}} 1 *$ cells is observed only in

20 ROR $\gamma$ T deficiency. We found that human T-bet was essential for both innate (NK cells) and innate-

21 like (iNKT, MAIT, and $\mathrm{V} \delta 2^{+} \gamma \delta \mathrm{T}$ cells) adaptive immunity to mycobacteria, but surprisingly

22 redundant for classical, purely adaptive immunity $\left(\mathrm{T}_{\mathrm{H}} 1^{*}\right)$ to mycobacteria. 
Acknowledgments

We thank the patients and their families; the members of the laboratory for helpful discussions; Tatiana Kochetkov for technical assistance; Benedetta Bigio for computing support; Cecilia Lindestam Arlehamn and Alessandro Sette for providing peptide pools, and Dominick Papandrea, Yelena Nemirovskaya, Mark Woollett, and Cécile Patissier for administrative assistance. We also thank the Flow Cytometry Resource Center for technical support and the Rockefeller University Hospital for patient-oriented support. These institutions are supported in part by the National Center for Advancing Translational Sciences of the National Institutes of Health (UL1TR001866 to Rockefeller University). We also thank Steven Elledge (Brigham and Women's Hospital, Harvard Medical School, Boston, MA, USA) for kindly providing the VirScan phage library used here for antibody profiling. This work was funded by the National Institute of Allergy and Infectious Diseases (R37AI095983 to J.L.C and U19AI118626 to F.S.), the Sackler Center for Biomedicine and Nutrition at the Center for Clinical and Translational Science, the Shapiro-Silverberg Fund for the Advancement of Translational Research at the Center for Clinical and Translational Science of the Rockefeller University (to R.Y.), the Research Grant Program of the Immune Deficiency Foundation (to R.Y.), the Integrative Biology of Emerging Infectious Diseases Laboratory of Excellence (ANR-10-LABX-62-IBEID) and the French National Research Agency under the "Investments for the future" program (ANR-10-IAHU-01), ANR-GENMSMD (ANR-16-CE17-0005-01 to J.B.), ANR-LTh-MSMD-CMCD (ANR-18-CE93-0008-01 to A.P), Fonds de Recherche en Santé Respiratoire (SRC2017 to J.B.), the French Foundation for Medical Research (FRM) (EQU201903007798), the SCOR Corporate Foundation for Science, ECOS Nord (C19S01-63407 to J.B.), the Swiss National Science Foundation (310030L_182728 to F.S.), the French Foundation for Medical Research (FRM) (EQU201903007798), the SCOR Corporate Foundation for Science, the St. Giles Foundation, the Rockefeller University, Howard Hughes Medical Institute, Institut National de la Santé et de la Recherche Médicale (INSERM), the Helmut Horten Foundation, Sidra Medicine and Paris Descartes University. The Canadian Center for Computational Genomics (C3G) is a Genomics Technology Platform (GTP) supported by the Canadian Government through Genome Canada. J. R. was supported by an INSERM Poste d'accueil. T.K. was supported by the Qatar National Research Fund (PPM1-1220-150017). S.G.T. was supported by a Program grant (1113904) and Principal Research Fellowship (1042925) awarded by the National Health and Medical Research Council of Australia. C.S.M. is supported by an Early/Mid-Career Development Research Fellowship (to C.S.M.) from the Ministry of Health of the NSW Government. R.Y. was supported in part by the Stony Wold-Herbert Fund and the Immune Deficiency Foundation. 


\section{Reference}

Acosta-Rodriguez, E. V, Rivino, L., Geginat, J., Jarrossay, D., Gattorno, M., Lanzavecchia, A., Sallusto, F., and Napolitani, G. (2007). Surface phenotype and antigenic specificity of human interleukin 17-producing T helper memory cells. Nat. Immunol. 8, 639-646.

Amir el, A.D., Davis, K.L., Tadmor, M.D., Simonds, E.F., Levine, J.H., Bendall, S.C., Shenfeld, D.K., Krishnaswamy, S., Nolan, G.P., and Pe'er, D. (2013). viSNE enables visualization of high dimensional single-cell data and reveals phenotypic heterogeneity of leukemia. Nat Biotechnol 31, 545-552.

Becattini, S., Latorre, D., Mele, F., Foglierini, M., De Gregorio, C., Cassotta, A., Fernandez, B., Kelderman, S., Schumacher, T.N., Corti, D., et al. (2015). T cell immunity. Functional heterogeneity of human memory $\mathrm{CD} 4(+) \mathrm{T}$ cell clones primed by pathogens or vaccines. Science (80-. ). 347, 400-406.

Becht, E., McInnes, L., Healy, J., Dutertre, C.-A., Kwok, I.W.H., Ng, L.G., Ginhoux, F., and Newell, E.W. (2019). Dimensionality reduction for visualizing single-cell data using UMAP. Nat. Biotechnol. 37, 38-44.

Bettelli, E., Sullivan, B., Szabo, S.J., Sobel, R.A., Glimcher, L.H., and Kuchroo, V.K. (2004). Loss of T-bet, but not STAT1, prevents the development of experimental autoimmune encephalomyelitis. J Exp Med 200, 79-87.

Björkström, N.K., Ljunggren, H.-G., and Sandberg, J.K. (2010). CD56 negative NK cells: origin, function, and role in chronic viral disease. Trends Immunol. 31, 401-406. Bogunovic, D., Byun, M., Durfee, L.A., Abhyankar, A., Sanal, O., Mansouri, D., Salem, S., Radovanovic, I., Grant, A. V, Adimi, P., et al. (2012). Mycobacterial disease and impaired IFNgamma immunity in humans with inherited ISG15 deficiency. Science (80-. ). 337, 1684-1688. Boisson-Dupuis, S., Ramirez-Alejo, N., Li, Z., Patin, E., Rao, G., Kerner, G., Lim, C.K., Krementsov, D.N., Hernandez, N., Ma, C.S., et al. (2018). Tuberculosis and impaired IL-23dependent IFN- $\gamma$ immunity in humans homozygous for a common TYK2 missense variant. Sci. Immunol. 3, eaau8714.

Bustamante, J., Boisson-Dupuis, S., Abel, L., and Casanova, J.L. (2014). Mendelian susceptibility to mycobacterial disease: genetic, immunological, and clinical features of inborn errors of IFN-gamma immunity. Semin Immunol 26, 454-470.

Casanova, J.-L. (2015a). Severe infectious diseases of childhood as monogenic inborn errors of immunity. Proc. Natl. Acad. Sci.

Casanova, J.-L. (2015b). Human genetic basis of interindividual variability in the course of infection. Proc. Natl. Acad. Sci.

Casanova, J.L. (1999). IL-12 and IFN- $\gamma$ in host defense against mycobacteria and salmonella in mice and men. Curr. Opin. Immunol. 11, 346-351. Casanova, J.L., and Abel, L. (2004). The human model: A genetic dissection of immunity to infection in natural conditions. Nat. Rev. Immunol. 4, 55-66.

Casanova, J.L., and Abel, L. (2018). Human genetics of infectious diseases: Unique insights into immunological redundancy. Semin. Immunol. 36, 1-12. Casanova, J.-L., Conley, M.E., Seligman, S.J., Abel, L., and Notarangelo, L.D. (2014). Guidelines for genetic studies in single patients: lessons from primary immunodeficiencies. J. Exp. Med. 211, 2137-2149.

44 Casanova, J.L., Jouanguy, E., Lamhamedi, S., Blanche, S., and Fischer, A. (1995).

45 Immunological conditions of children with BCG disseminated infection. Lancet (London, 46 England) 346, 581. 
Casey, J.P., Nobbs, M., McGettigan, P., Lynch, S., and Ennis, S. (2012). Recessive mutations in MCM4/PRKDC cause a novel syndrome involving a primary immunodeficiency and a disorder of DNA repair. J. Med. Genet. 49, 242-245. Chen, Z.W. (2005). Immune regulation of gammadelta $\mathrm{T}$ cell responses in mycobacterial infections. Clin. Immunol. 116, 202-207.

Chen, X., and Prywes, R. (1999). Serum-induced expression of the cdc25A gene by relief of E2F-mediated repression. Mol. Cell. Biol. 19, 4695-4702. Chen, L., He, W., Kim, S.T., Tao, J., Gao, Y., Chi, H., Intlekofer, A.M., Harvey, B., Reiner, S.L., Yin, Z., et al. (2007). Epigenetic and Transcriptional Programs Lead to Default IFN- $\gamma$ Production by $\gamma \delta$ T Cells. J. Immunol. 178, 2730-2736. Chien, Y., Meyer, C., and Bonneville, M. (2014). $\gamma \delta$ T Cells: First Line of Defense and Beyond. Annu. Rev. Immunol. 32, 121-155. Consortium, T. 1000 G.P. (2015). A global reference for human genetic variation. Nature 526, 68-74.

Corces, M.R., Trevino, A.E., Hamilton, E.G., Greenside, P.G., Sinnott-Armstrong, N.A., Vesuna, S., Satpathy, A.T., Rubin, A.J., Montine, K.S., Wu, B., et al. (2017). An improved ATAC-seq protocol reduces background and enables interrogation of frozen tissues. Nat. Methods 14, 959-962. Cottineau, J., Kottemann, M.C., Lach, F.P., Kang, Y.-H., Vély, F., Deenick, E.K., Lazarov, T., Gineau, L., Wang, Y., Farina, A., et al. (2017). Inherited GINS1 deficiency underlies growth retardation along with neutropenia and NK cell deficiency. J. Clin. Invest. 127, 1991-2006. Crosby, C.M., and Kronenberg, M. (2018). Tissue-specific functions of invariant natural killer T cells. Nat. Rev. Immunol. 18, 559-574.

Davis, B.R., Dicola, M.J., Prokopishyn, N.L., Rosenberg, J.B., Moratto, D., Muul, L.M., Candotti, F., and Michael Blaese, R. (2008). Unprecedented diversity of genotypic revertants in lymphocytes of a patient with Wiskott-Aldrich syndrome. Blood 111, 5064-5067. Dorner, B.G., Scheffold, A., Rolph, M.S., Huser, M.B., Kaufmann, S.H.E., Radbruch, A., Flesch, I.E.A., and Kroczek, R.A. (2002). MIP-1 , MIP-1 , RANTES, and ATAC/lymphotactin function together with IFN- as type 1 cytokines. Proc. Natl. Acad. Sci. 99, 6181-6186. analysis of the murine chemokines MIP-1alpha, MIP-1beta, RANTES and ATAC/lymphotactin by flow cytometry. J. Immunol. Methods 274, 83-91.

Dorner, B.G., Smith, H.R.C., French, A.R., Kim, S., Poursine-Laurent, J., Beckman, D.L., Pingel, J.T., Kroczek, R.A., and Yokoyama, W.M. (2004). Coordinate Expression of Cytokines and Chemokines by NK Cells during Murine Cytomegalovirus Infection. J. Immunol. 172, 3119-3131.

Dupuis, S., Döffinger, R., Picard, C., Fieschi, C., Altare, F., Jouanguy, E., Abel, L., and Casanova, J.L. (2000). Human interferon-gamma-mediated immunity is a genetically controlled continuous trait that determines the outcome of mycobacterial invasion. Immunol. Rev. 178,

$40 \quad 129-137$.

41 Garrett, W.S., Lord, G.M., Punit, S., Lugo-Villarino, G., Mazmanian, S.K., Ito, S., Glickman, J.N., and Glimcher, L.H. (2007). Communicable ulcerative colitis induced by T-bet deficiency in the innate immune system. Cell 131,33-45.

44 Gavins, F.N.E., and Hickey, M.J. (2012). Annexin A1 and the regulation of innate and adaptive 45 immunity. Front. Immunol. 3, 354.

46 Geiger, R., Duhen, T., Lanzavecchia, A., and Sallusto, F. (2009). Human naive and memory 
CD4+ T cell repertoires specific for naturally processed antigens analyzed using libraries of amplified T cells. J. Exp. Med. 206, 1525-1534.

Gineau, L., Cognet, C., Kara, N., Lach, F.P., Dunne, J., Veturi, U., Picard, C., Trouillet, C., Eidenschenk, C., Aoufouchi, S., et al. (2012). Partial MCM4 deficiency in patients with growth retardation, adrenal insufficiency, and natural killer cell deficiency. J. Clin. Invest. 122, 821-832. Godfrey, D.I., Koay, H.-F., McCluskey, J., and Gherardin, N.A. (2019). The biology and functional importance of MAIT cells. Nat. Immunol. 20, 1110-1128.

Gokmen, M.R., Dong, R., Kanhere, A., Powell, N., Perucha, E., Jackson, I., Howard, J.K., Hernandez-Fuentes, M., Jenner, R.G., and Lord, G.M. (2013). Genome-Wide Regulatory Analysis Reveals That T-bet Controls Th17 Lineage Differentiation through Direct Suppression of IRF4. J. Immunol.

Groom, J.R., and Luster, A.D. (2011). CXCR3 in T cell function. Exp. Cell Res. 317, 620-631. Gu, S., Borowska, M.T., Boughter, C.T., and Adams, E.J. (2018). Butyrophilin3A proteins and Vy9V82 T cell activation. Semin. Cell Dev. Biol. 84, 65-74. Hambleton, S., Salem, S., Bustamante, J., Bigley, V., Boisson-Dupuis, S., Azevedo, J., Fortin, A., Haniffa, M., Ceron-Gutierrez, L., Bacon, C.M., et al. (2011). IRF8 Mutations and Human Dendritic-Cell Immunodeficiency . N. Engl. J. Med. Harly, C., Guillaume, Y., Nedellec, S., Peigne, C.M., Monkkonen, H., Monkkonen, J., Li, J., Kuball, J., Adams, E.J., Netzer, S., et al. (2012). Key implication of CD277/butyrophilin-3 (BTN3A) in cellular stress sensing by a major human gammadelta T-cell subset. Blood 120, 2269-2279.

Hoft, D.F., Brown, R.M., and Roodman, S.T. (1998). Bacille Calmette-Guerin vaccination enhances human gamma delta $\mathrm{T}$ cell responsiveness to mycobacteria suggestive of a memorylike phenotype. J Immunol 161, 1045-1054.

Hughes, C.R., Guasti, L., Meimaridou, E., Chuang, C.-H., Schimenti, J.C., King, P.J., Costigan, C., Clark, A.J.L., and Metherell, L.A. (2012). MCM4 mutation causes adrenal failure, short stature, and natural killer cell deficiency in humans. J. Clin. Invest. 122, 814-820. Itan, Y., Zhang, S.-Y., Vogt, G., Abhyankar, A., Herman, M., Nitschke, P., Fried, D., QuintanaMurci, L., Abel, L., and Casanova, J.-L. (2013). The human gene connectome as a map of short cuts for morbid allele discovery. Proc. Natl. Acad. Sci. 110, 5558-5563. Itan, Y., Mazel, M., Mazel, B., Abhyankar, A., Nitschke, P., Quintana-Murci, L., BoissonDupuis, S., Boisson, B., Abel, L., Zhang, S.-Y., et al. (2014). HGCS: an online tool for prioritizing disease-causing gene variants by biological distance. BMC Genomics 15, 256. Itan, Y., Shang, L., Boisson, B., Patin, E., Bolze, A., Moncada-Velez, M., Scott, E., Ciancanelli, M.J., Lafaille, F.G., Markle, J.G., et al. (2015). The human gene damage index as a gene-level approach to prioritizing exome variants. Proc Natl Acad Sci U S A 112, 13615-13620. Itan, Y., Shang, L., Boisson, B., Ciancanelli, M.J., Markle, J.G., Martinez-Barricarte, R., Scott, E., Shah, I., Stenson, P.D., Gleeson, J., et al. (2016). The mutation significance cutoff: gene-level thresholds for variant predictions. Nat Methods 13, 109-110. Iwata, S., Mikami, Y., Sun, H.-W., Brooks, S.R., Jankovic, D., Hirahara, K., Onodera, A., Shih, H.-Y., Kawabe, T., Jiang, K., et al. (2017). The Transcription Factor T-bet Limits Amplification of Type I IFN Transcriptome and Circuitry in T Helper 1 Cells. Immunity 46, 983-991.e4. Janesick, A., Shiotsugu, J., Taketani, M., and Blumberg, B. (2012). RIPPLY3 is a retinoic acidinducible repressor required for setting the borders of the pre-placodal ectoderm. Development $45 \quad 139,1213-1224$.

46 Jang, E.J., Park, H.R., Hong, J.H., and Hwang, E.S. (2013). Lysine 313 of T-box is crucial for 
modulation of protein stability, DNA binding, and threonine phosphorylation of T-bet. J Immunol 190, 5764-5770.

Jenner, R.G., Townsend, M.J., Jackson, I., Sun, K., Bouwman, R.D., Young, R.A., Glimcher, L.H., and Lord, G.M. (2009). The transcription factors T-bet and GATA-3 control alternative pathways of T-cell differentiation through a shared set of target genes. Proc. Natl. Acad. Sci. U. S. A. 106, 17876-17881.

Juedes, A.E., Rodrigo, E., Togher, L., Glimcher, L.H., and von Herrath, M.G. (2004). T-bet controls autoaggressive CD8 lymphocyte responses in type 1 diabetes. J Exp Med 199, 11531162.

Kanhere, A., Hertweck, A., Bhatia, U., Gökmen, M.R., Perucha, E., Jackson, I., Lord, G.M., and Jenner, R.G. (2012). T-bet and GATA3 orchestrate Th1 and Th2 differentiation through lineagespecific targeting of distal regulatory elements. Nat. Commun. 3, 1268. Karczewski, K., Francioli, L., Tiao, G., Cummings, B., Alföldi, J., Wang, Q., Collins, R., Laricchia, K., Ganna, A., Birnbaum, D., et al. (2019). Variation across 141,456 human exomes and genomes reveals the spectrum of loss-of-function intolerance across human protein-coding genes: Supplementary Information.

Kircher, M., Witten, D.M., Jain, P., O’Roak, B.J., Cooper, G.M., and Shendure, J. (2014). A general framework for estimating the relative pathogenicity of human genetic variants. Nat Genet 46, 310-315. Kjer-Nielsen, L., Patel, O., Corbett, A.J., Nours, J. Le, Meehan, B., Liu, L., Bhati, M., Chen, Z., Kostenko, L., Reantragoon, R., et al. (2012). MR1 presents microbial vitamin B metabolites to MAIT cells _ Nature Nature Research. Nature. Koch, M.A., Tucker-Heard, G., Perdue, N.R., Killebrew, J.R., Urdahl, K.B., and Campbell, D.J. (2009). The transcription factor T-bet controls regulatory $\mathrm{T}$ cell homeostasis and function during type 1 inflammation. Nat. Immunol. 10, 595-602.

Kong, X.F., Martinez-Barricarte, R., Kennedy, J., Mele, F., Lazarov, T., Deenick, E.K., Ma, C.S., Breton, G., Lucero, K.B., Langlais, D., et al. (2018). Disruption of an antimycobacterial circuit between dendritic and helper T cells in human SPPL2a deficiency. Nat Immunol 19, 973985.

Kroczek, R.A., and Henn, V. (2012). The Role of XCR1 and its Ligand XCL1 in Antigen CrossPresentation by Murine and Human Dendritic Cells. Front. Immunol. 3, 14. Latour, S. (2007). Natural killer T cells and X-linked lymphoproliferative syndrome. Curr. Opin. Allergy Clin. Immunol. 7, 510-514. V.K., and Glimcher, L.H. (2011). T-bet represses TH 17 differentiation by preventing Runx1mediated activation of the gene encoding ROR $\gamma$ t. Nat. Immunol. Lazarevic, V., Glimcher, L.H., and Lord, G.M. (2013). T-bet: a bridge between innate and adaptive immunity. Nat Rev Immunol 13, 777-789. Putintseva, E. V, Chaudhry, A., Dikiy, S., et al. (2017). Stability and function of regulatory T cells expressing the transcription factor T-bet. Nature 546, 421-425.

Lewis, M.D., Miller, S.A., Miazgowicz, M.M., Beima, K.M., and Weinmann, A.S. (2007). Tbet's ability to regulate individual target genes requires the conserved T-box domain to recruit histone methyltransferase activity and a separate family member-specific transactivation domain. Mol. Cell. Biol. 27, 8510-8521. 
A., Bustamante, J., Surace, L., et al. (2017). Systemic Human ILC Precursors Provide a Substrate for Tissue ILC Differentiation. Cell 168, 1086-1100.e10.

Locci, M., Ghici, E.D., Marangoni, F., Bosticardo, M., Catucci, M., Aiuti, A., Cancrini, C., Marodi, L., Espanol, T., Bredius, R.G.M., et al. (2009). The Wiskott-Aldrich syndrome protein is required for iNKT cell maturation and function. J. Exp. Med. 206, 735-742.

Loetscher, P., Uguccioni, M., Bordoli, L., Baggiolini, M., Moser, B., Chizzolini, C., and Dayer, J.-M. (1998). CCR5 is characteristic of Th1 lymphocytes. Nature 391, 344-345.

Lund, R., Ahlfors, H., Kainonen, E., Lahesmaa, A.-M., Dixon, C., and Lahesmaa, R. (2005). Identification of genes involved in the initiation of human Th1 or Th2 cell commitment. Eur. J. Immunol. 35, 3307-3319.

Martínez-Barricarte, R., Markle, J.G., Ma, C.S., Deenick, E.K., Ramírez-Alejo, N., Mele, F., Latorre, D., Mahdaviani, S.A., Aytekin, C., Mansouri, D., et al. (2018). Human IFN- immunity to mycobacteria is governed by both IL-12 and IL-23. Sci. Immunol.

Matsuyama, M., Ishii, Y., Yageta, Y., Ohtsuka, S., Ano, S., Matsuno, Y., Morishima, Y., Yoh, K., Takahashi, S., Ogawa, K., et al. (2014). Role of Th1/Th17 balance regulated by T-bet in a mouse model of Mycobacterium avium complex disease. J Immunol 192, 1707-1717.

Miller, S.A., and Weinmann, A.S. (2010). Molecular mechanisms by which T-bet regulates Thelper cell commitment. Immunol Rev 238, 233-246.

Modlin, R.L., Pirmez, C., Hofman, F.M., Torigian, V., Uyemura, K., Rea, T.H., Bloom, B.R., and Brenner, M.B. (1989). Lymphocytes bearing antigen-specific $\gamma \delta$ T-cell receptors accumulate in human infectious disease lesions. Nature 339, 544-548.

Morgan, N. V., Goddard, S., Cardno, T.S., McDonald, D., Rahman, F., Barge, D., Ciupek, A., Straatman-Iwanowska, A., Pasha, S., Guckian, M., et al. (2011). Mutation in the TCR $\alpha$ subunit constant gene (TRAC) leads to a human immunodeficiency disorder characterized by a lack of TCR $\alpha \beta+$ T cells. J. Clin. Invest. 121, 695-702.

Nathan, C.F., Murray, H.W., Wiebe, M.E., and Rubin, B.Y. (1983). Identification of interferongamma as the lymphokine that activates human macrophage oxidative metabolism and antimicrobial activity. J Exp Med 158, 670-689.

Nishikomori, R., Usui, T., Wu, C.-Y., Morinobu, A., O’Shea, J.J., and Strober, W. (2002). Activated STAT4 has an essential role in Th1 differentiation and proliferation that is independent of its role in the maintenance of IL-12R beta 2 chain expression and signaling. J. Immunol. 169, 4388-4398.

Okada, S., Markle, J.G., Deenick, E.K., Mele, F., Averbuch, D., Lagos, M., Alzahrani, M., AlMuhsen, S., Halwani, R., Ma, C.S., et al. (2015). Impairment of immunity to Candida and Mycobacterium in humans with bi-allelic RORC mutations. Science (80-. ). 349, 606-613. Panchamoorthy, G., McLean, J., Modlin, R.L., Morita, C.T., Ishikawa, S., Brenner, M.B., and Band, H. (1991). A predominance of the $\mathrm{T}$ cell receptor $\mathrm{V}$ gamma 2/V delta 2 subset in human mycobacteria-responsive T cells suggests germline gene encoded recognition. J. Immunol. 147, 3360-3369.

40 Parker, C.M., Groh, V., Band, H., Porcelli, S.A., Morita, C., Fabbi, M., Glass, D., Strominger, J.L., and Brenner, M.B. (1990). Evidence for extrathymic changes in the T cell receptor gamma/delta repertoire. J. Exp. Med. 171, 1597-1612.

Petrovski, S., Gussow, A.B., Wang, Q., Halvorsen, M., Han, Y., Weir, W.H., Allen, A.S., and Goldstein, D.B. (2015). The Intolerance of Regulatory Sequence to Genetic Variation Predicts 45 Gene Dosage Sensitivity. PLoS Genet 11, e1005492.

46 Powell, N., Walker, A.W., Stolarczyk, E., Canavan, J.B., Gökmen, M.R., Marks, E., Jackson, I., 
Hashim, A., Curtis, M.A., Jenner, R.G., et al. (2012). The Transcription Factor T-bet Regulates Intestinal Inflammation Mediated by Interleukin-7 Receptor+ Innate Lymphoid Cells. Immunity 37, 674-684.

Revy, P., Kannengiesser, C., and Fischer, A. (2019). Somatic genetic rescue in Mendelian haematopoietic diseases. Nat. Rev. Genet. 20, 582-598.

Rosain, J., Kong, X.F., Martinez-Barricarte, R., Oleaga-Quintas, C., Ramirez-Alejo, N., Markle, J., Okada, S., Boisson-Dupuis, S., Casanova, J.L., and Bustamante, J. (2019). Mendelian susceptibility to mycobacterial disease: 2014-2018 update. Immunol. Cell Biol. Salem, S., Langlais, D., Lefebvre, F., Bourque, G., Bigley, V., Haniffa, M., Casanova, J.-L., Burk, D., Berghuis, A., Butler, K.M., et al. (2014). Functional characterization of the human dendritic cell immunodeficiency associated with the IRF8(K108E) mutation. Blood 124, 18941904.

Sallusto, F., Lenig, D., Mackay, C.R., and Lanzavecchia, A. (1998). Flexible Programs of Chemokine Receptor Expression on Human Polarized T Helper 1 and 2 Lymphocytes. J. Exp. Med. 187, 875-883.

Scott, E.M., Halees, A., Itan, Y., Spencer, E.G., He, Y., Azab, M.A., Gabriel, S.B., Belkadi, A., Boisson, B., Abel, L., et al. (2016). Characterization of Greater Middle Eastern genetic variation for enhanced disease gene discovery. Nat. Genet. 48, 1071-1076. Shen, Y., Zhou, D., Qiu, L., Lai, X., Simon, M., Shen, L., Kou, Z., Wang, Q., Jiang, L., Estep, J., et al. (2002). Adaptive immune response of Vgamma2Vdelta2+ T cells during mycobacterial infections. Science (80-. ). 295, 2255-2258. Soutto, M., Zhang, F., Enerson, B., Tong, Y., Boothby, M., and Aune, T.M. (2002). A minimal IFN-gamma promoter confers Th1 selective expression. J Immunol 169, 4205-4212. Sullivan, B.M., Juedes, A., Szabo, S.J., von Herrath, M., and Glimcher, L.H. (2003). Antigendriven effector CD8 T cell function regulated by T-bet. Proc. Natl. Acad. Sci.

Sullivan, B.M., Jobe, O., Lazarevic, V., Vasquez, K., Bronson, R., Glimcher, L.H., and Kramnik, I. (2005). Increased susceptibility of mice lacking T-bet to infection with Mycobacterium tuberculosis correlates with increased IL-10 and decreased IFN-gamma production. J Immunol $175,4593-4602$.

Szabo, S.J., Kim, S.T., Costa, G.L., Zhang, X., Fathman, C.G., and Glimcher, L.H. (2000). A novel transcription factor, T-bet, directs Th1 lineage commitment. Cell 100, 655-669. Szabo, S.J., Sullivan, B.M., Stemmann, C., Satoskar, A.R., Sleckman, B.P., and Glimcher, L.H. (2002). Distinct effects of T-bet in TH1 lineage commitment and IFN-gamma production in CD4 and CD8 T cells. Science (80-. ). 295, 338-342.

Taliun, D., Harris, D.N., Kessler, M.D., Carlson, J., Szpiech, Z.A., Torres, R., Taliun, S.A.G., Corvelo, A., Gogarten, S.M., Kang, H.M., et al. (2019). Sequencing of 53,831 diverse genomes from the NHLBI TOPMed Program. BioRxiv 563866. Tan, T.G., Mathis, D., and Benoist, C. (2016). Singular role for T-BET + CXCR3 + regulatory T cells in protection from autoimmune diabetes . Proc. Natl. Acad. Sci.

40 Tangye, S.G., Palendira, U., and Edwards, E.S.J. (2017). Human immunity against EBV-

41 lessons from the clinic. J. Exp. Med. 214, 269-283.

42 Tantisira, K.G., Hwang, E.S., Raby, B.A., Silverman, E.S., Lake, S.L., Richter, B.G., Peng, S.L., 43 Drazen, J.M., Glimcher, L.H., and Weiss, S.T. (2004). TBX21: a functional variant predicts improvement in asthma with the use of inhaled corticosteroids. Proc Natl Acad Sci U S A 101, 18099-18104.

46 Thieu, V.T., Yu, Q., Chang, H.-C., Yeh, N., Nguyen, E.T., Sehra, S., and Kaplan, M.H. (2008). 
Signal transducer and activator of transcription 4 is required for the transcription factor T-bet to promote T helper 1 cell-fate determination. Immunity 29, 679-690.

Tong, Y., Aune, T., and Boothby, M. (2005a). T-bet antagonizes mSin3a recruitment and transactivates a fully methylated IFN-gamma promoter via a conserved T-box half-site. Proc Natl Acad Sci U S A 102, 2034-2039.

Tong, Y., Aune, T., and Boothby, M. (2005b). T-bet antagonizes mSin3a recruitment and transactivates a fully methylated IFN- promoter via a conserved T-box half-site. Proc. Natl. Acad. Sci.

Toribio-Fernández, R., Zorita, V., Rocha-Perugini, V., Iborra, S., Martínez del Hoyo, G., Chevre, R., Dorado, B., Sancho, D., Sanchez-Madrid, F., Andrés, V., et al. (2018). Lamin A/C augments Th1 differentiation and response against vaccinia virus and Leishmania major. Cell Death Dis. 9, 9.

Townsend, M.J., Weinmann, A.S., Matsuda, J.L., Salomon, R., Farnham, P.J., Biron, C.A., Gapin, L., and Glimcher, L.H. (2004). T-bet regulates the terminal maturation and homeostasis of NK and Valpha14i NKT cells. Immunity 20, 477-494.

Tsukaguchi, K., Balaji, K.N., and Boom, W.H. (1995). CD4+ alpha beta T cell and gamma delta T cell responses to Mycobacterium tuberculosis. Similarities and differences in Ag recognition, cytotoxic effector function, and cytokine production. J. Immunol. 154, 1786-1796.

Vavassori, S., Kumar, A., Wan, G.S., Ramanjaneyulu, G.S., Cavallari, M., El Daker, S., Beddoe, T., Theodossis, A., Williams, N.K., Gostick, E., et al. (2013). Butyrophilin 3A1 binds phosphorylated antigens and stimulates human gammadelta T cells. Nat Immunol 14, 908-916. Velu, V., Mylvaganam, G.H., Gangadhara, S., Hong, J.J., Iyer, S.S., Gumber, S., Ibegbu, C.C., Villinger, F., and Amara, R.R. (2016). Induction of Th1-Biased T Follicular Helper (Tfh) Cells in Lymphoid Tissues during Chronic Simian Immunodeficiency Virus Infection Defines Functionally Distinct Germinal Center Tfh Cells. J. Immunol. 197, 1832-1842. Wilson, C.B., and Schoenborn, J.R. (2007). Regulation of Interferon-g During Innate and Adaptive Immune Responses. Adv. Immunol.

Xiao, X., and Cai, J. (2017). Mucosal-associated invariant T cells: New insights into antigen recognition and activation. Front. Immunol. Yoshitomi, H., Kobayashi, S., Miyagawa-Hayashino, A., Okahata, A., Doi, K., Nishitani, K., Murata, K., Ito, H., Tsuruyama, T., Haga, H., et al. (2018). Human Sox4 facilitates the development of CXCL13-producing helper T cells in inflammatory environments. Nat. Commun. 9, 3762. Yu, J., Wei, M., Becknell, B., Trotta, R., Liu, S., Boyd, Z., Jaung, M.S., Blaser, B.W., Sun, J., Benson Jr., D.M., et al. (2006). Pro- and antiinflammatory cytokine signaling: reciprocal antagonism regulates interferon-gamma production by human natural killer cells. Immunity 24 , 575-590. Zhang, J., Liu, W., Wen, B., Xie, T., Tang, P., Hu, Y., Huang, L., Jin, K., Zhang, P., Liu, Z., et al. (2019a). Circulating CXCR3+ Tfh cells positively correlate with neutralizing antibody responses in HCV-infected patients. Sci. Rep. 9, 10090. Zhang, P., Bigio, B., Rapaport, F., Zhang, S.-Y., Casanova, J.-L., Abel, L., Boisson, B., and Itan, Y. (2018). PopViz: a webserver for visualizing minor allele frequencies and damage prediction scores of human genetic variations. Bioinformatics 34, 4307-4309. 
1 Zhang, Y., Siegel, A.M., Sun, G., Dimaggio, T., Freeman, A.F., and Milner, J.D. (2019b).

2 Human TH9 differentiation is dependent on signal transducer and activator of transcription

3 (STAT) 3 to restrain STAT1-mediated inhibition. J. Allergy Clin. Immunol. 143, 1108-1118.e4.

4 Zheng, W., and Flavell, R.A. (1997). The transcription factor GATA-3 is necessary and

5 sufficient for Th2 cytokine gene expression in CD4 T cells. Cell 89, 587-596.

6 Zhu, J., Yamane, H., and Paul, W.E. (2010). Differentiation of Effector CD4 T Cell Populations.

7 Annu. Rev. Immunol. 28, 445-489. 
bioRxiv preprint doi: https://doi.org/10.1101/2020.08.31.274589; this version posted August 31, 2020. The copyright holder for this preprint (which was not certified by peer review) is the author/funder, who has granted bioRxiv a license to display the preprint in perpetuity. It is made available under aCC-BY-NC-ND 4.0 International license.

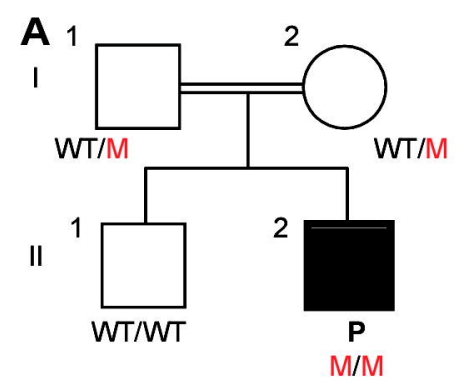

c.466_471delinsAGTTTA (c.466_471delGAGATGinsAGTTTA)
B T-bet (TBX21) T-box domain

\begin{tabular}{lllll}
\multicolumn{1}{l}{ H.sapiens } & 151 & NQHQTEMIITKQGRRMFPFLSFTVAGLEPTSHYRMFVDVVLVDQHHWRY & 200 \\
P.troglodytes & 151 & NQHQTEMIITKQGRRMFPFLSFTVAGLEPTSHYRMFVDVLVDQHHWRY & 200 \\
M.mulatta & 151 & NQHQTEMIITKQGRRMFPFLSFTVAGLEPTSHYRMFVDVLVDQHHWRY & 200 \\
C.lupus & 151 & NQHQTEMIITKQGRRMFPFLSFTVAGLEPTSHYRMFVDVLVDQHHWRY & 200 \\
B.taurus & 151 & NQHQTEMIITKQGRRMFPFSFTVAGLEPNSHYRMYVVVLVDQHHWRY & 200 \\
M.musculus & 150 & NQHQTEMIITKQGRRMFPFLSFTVAGLEPTSHYRMFVDVLVDQHHWRY & 199 \\
R.norvegicus & 150 & NQHQTEMIITKQGRRMFPFLSFTVAGLEPTSHYRMFVDVLVDQHHWRY & 199
\end{tabular}

C

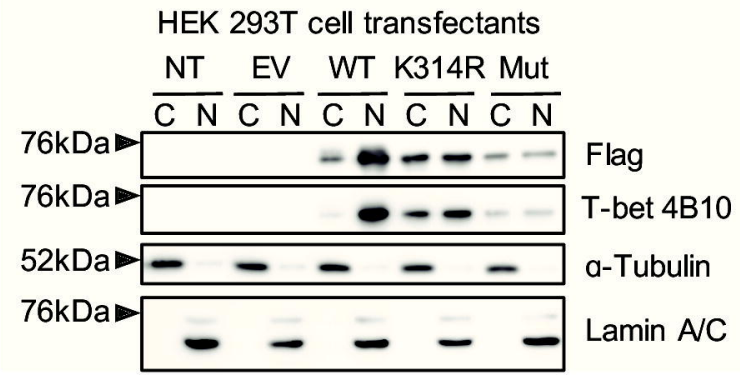

D

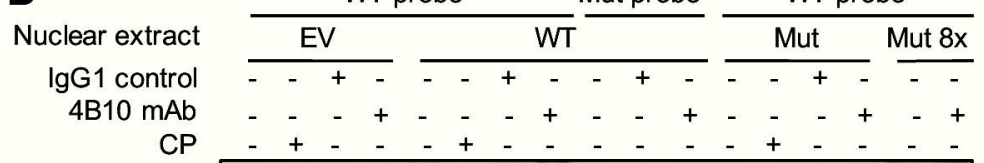

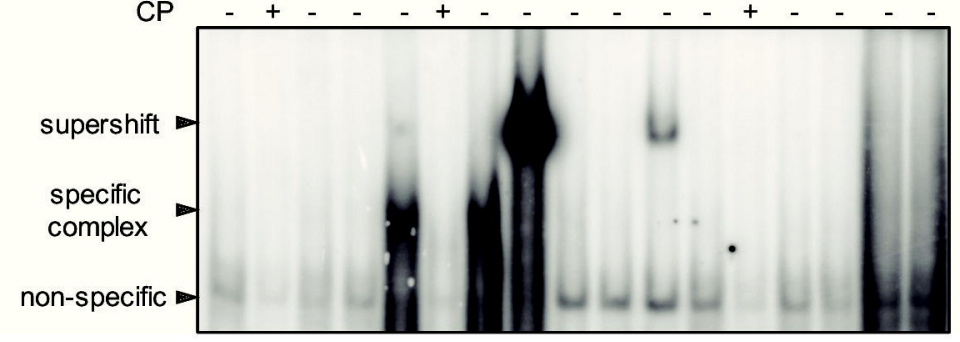

E

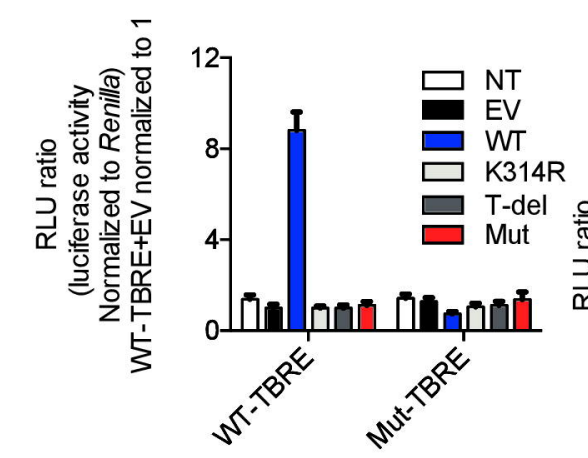

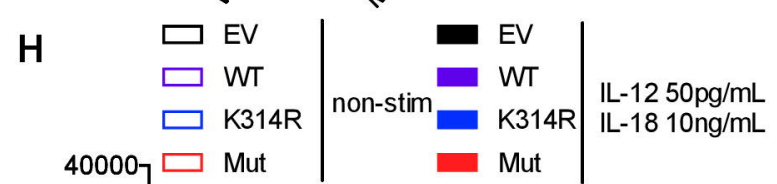

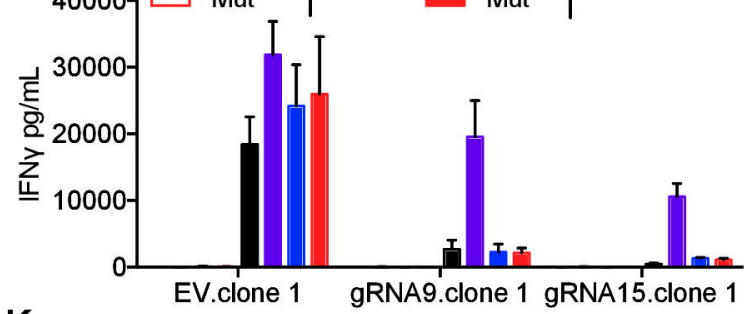

K

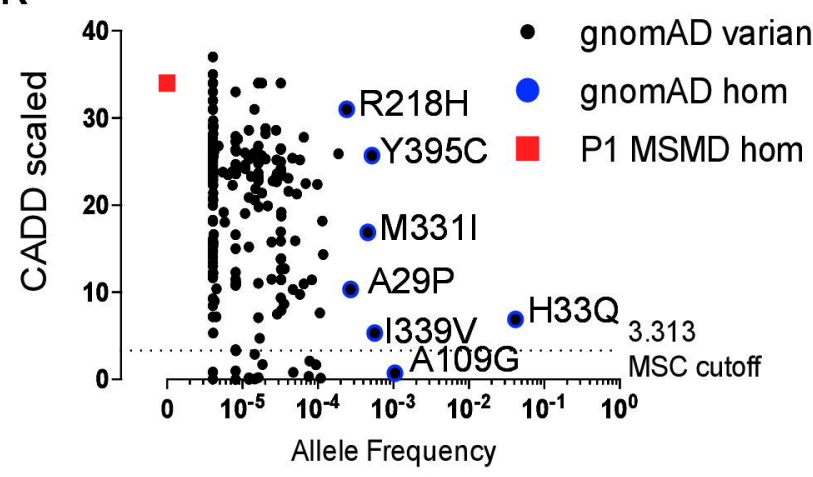

$\mathbf{F}$

휸

그류 pGL4.10 EV + WT T-bet $\square$ pGL4.10 plFNg + T-del T-bet
pGL4.10 plFNg + WT T-bet $\square$ pGL4.10 plFNg + Mut T-bet
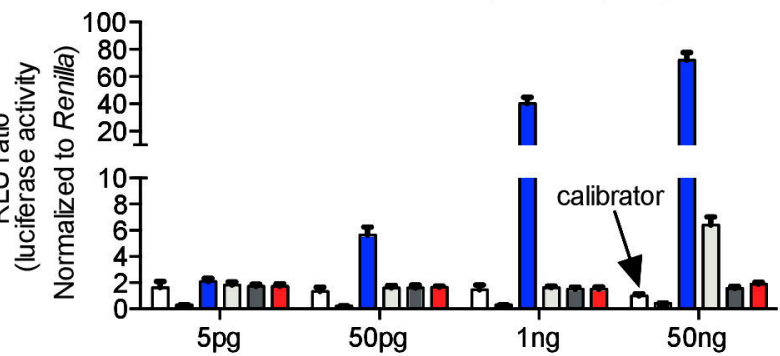

I

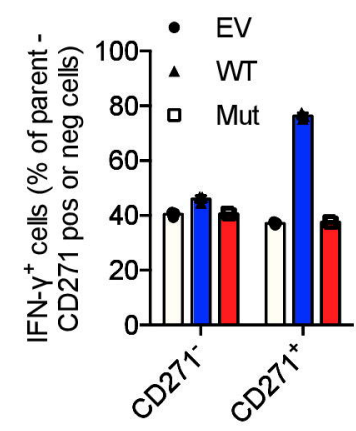

L

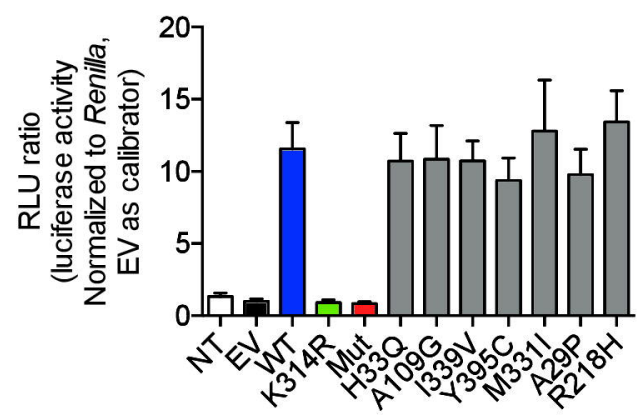

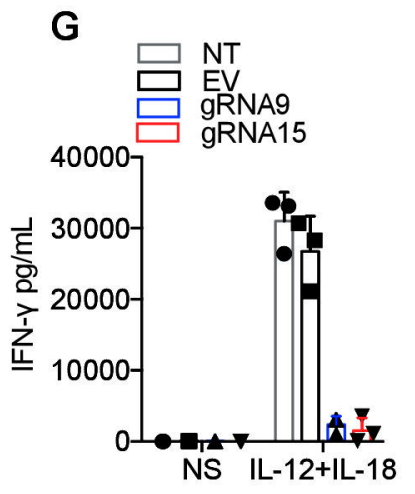

J

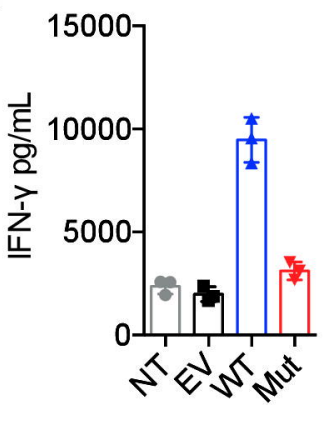


bioRxiv preprint doi: https://doi.org/10.1101/2020.08.31.274589; this version posted August 31, 2020. The copyright holder for this preprint (which was not certified by peer review) is the author/funder, who has granted bioRxiv a license to display the preprint in perpetuity. It is made available under aCC-BY-NC-ND 4.0 International license.

A

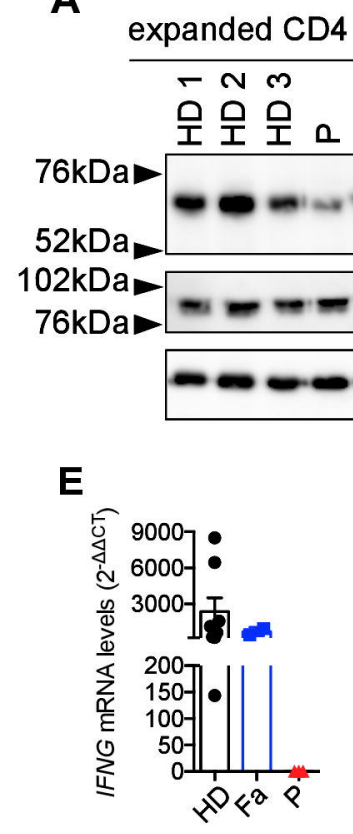

H

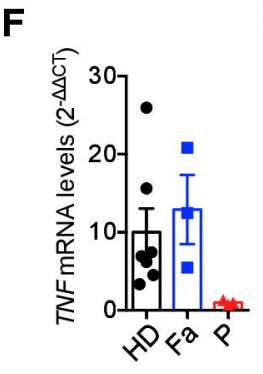

B

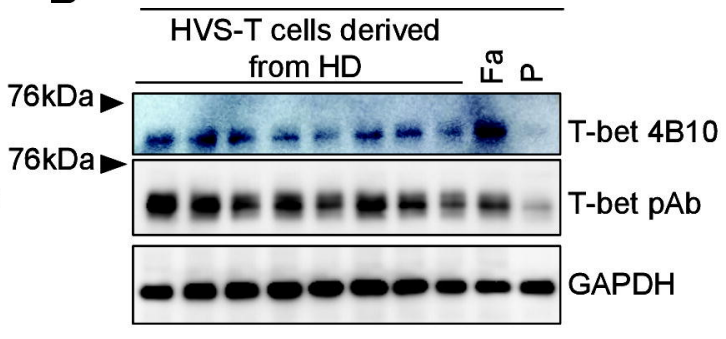

- HD T-saimiri $>\mathrm{P}+\mathrm{EV}$

- TBX21 wt/mFa $\quad \mathrm{P}+\mathrm{WTT}$-bet

G $\triangle T B X 21 \mathrm{~m} / \mathrm{mP}$

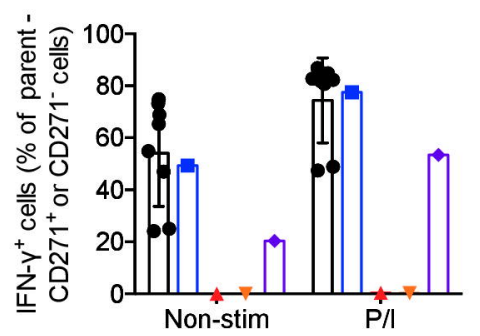

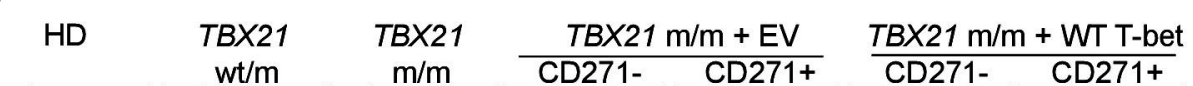
$54 \% 32.8 \% 53 \% \quad 26.5 \% 54 \% 1.86 \% \quad 53 \% 2.97 \%$ 53\% $4.11 \% 57 \% 8.27 \% 27 \% 55.1 \%$

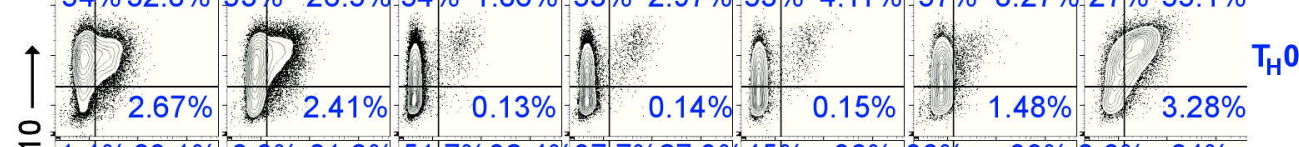

은 $1.4 \% 83.1 \% \quad 0.9 \% 81.8 \% 51.7 \% 32.4 \% 37.7 \% 27.3 \% 45 \% \quad 30 \% \quad 36 \% \quad 39 \% 8.6 \% \quad 84 \%$

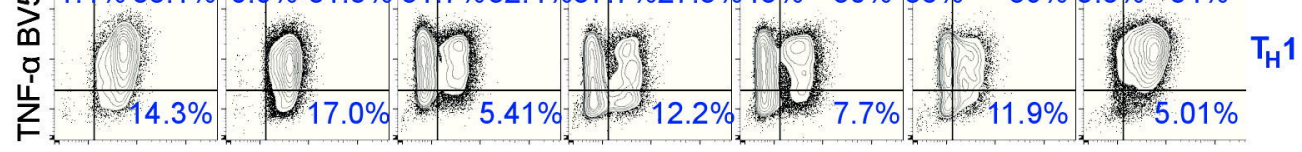
IFN-y PERCP/Cy5.5 $\longrightarrow$

I

- HD T-saimiri $P+E V$

- $T B X 21 \mathrm{wt} / \mathrm{mFa}$. P + WT T-bet

- TBX21 m/m P
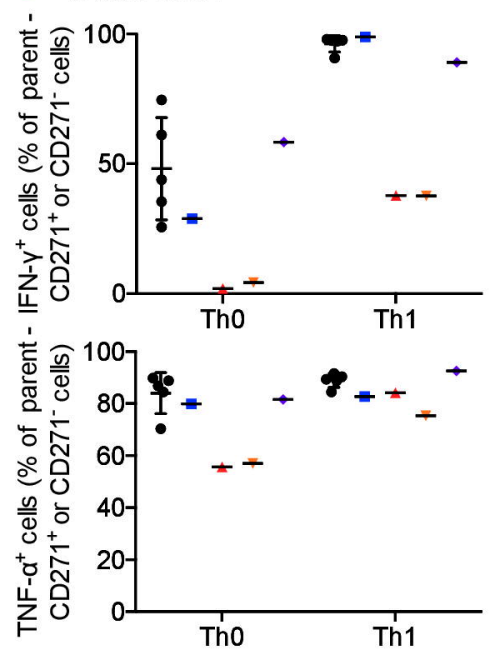

J
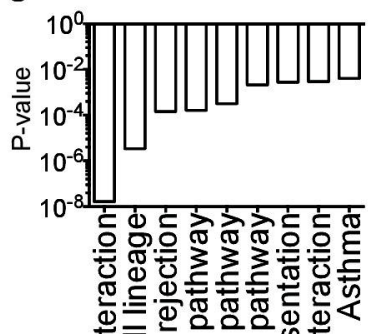

焉.․ㅡ.

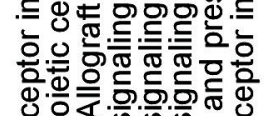

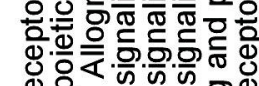

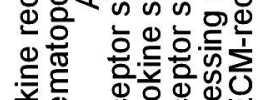

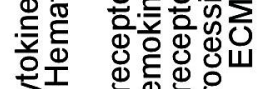

氷

旁
C

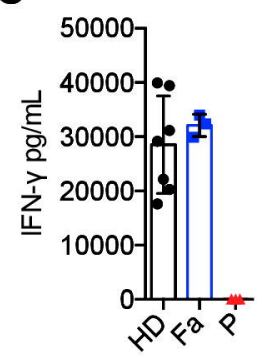

D

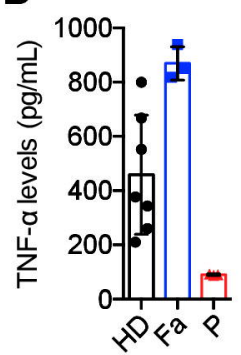

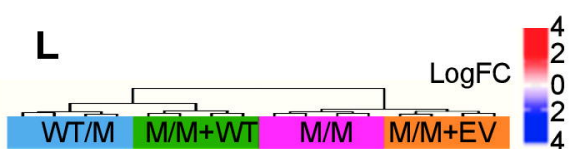

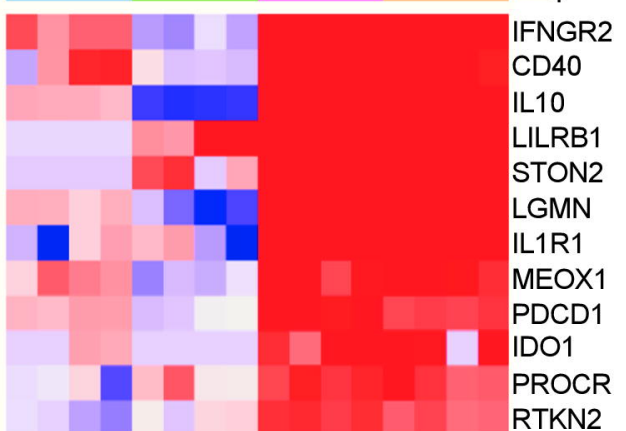

PIK3AP1

KLRC4

KLRK1

THBS1

FES

GZMM

PTK2

TBKBP1

CITED1

NTRK1

K

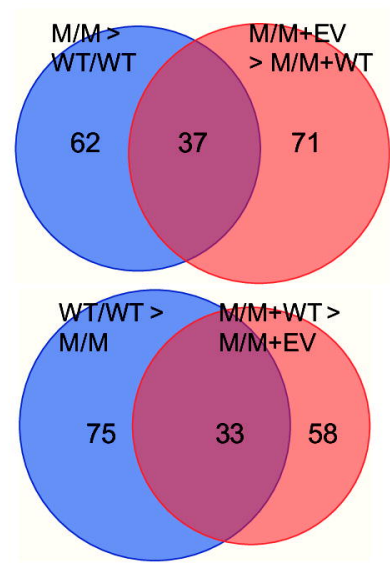

NLRP6

CD1C

CXCR3

IL7R

ITGA5

CXCR5

LTB

LTA

JAG1

ULBP1

CCL3

CCL4

ITGB5

TNF

CSF2

IFNG

MID2

INHBA

CCL13

IL 8

CCL1 
bioRxiv preprint doi: https://doi.org/10.1101/2020.08.31.274589; this version posted August 31, 2020. The copyright holder for this preprint (which was not certified by peer review) is the author/funder, who has granted bioRxiv a license to display the preprint in perpetuity. It is made available under aCC-BY-NC-ND 4.0 International license.
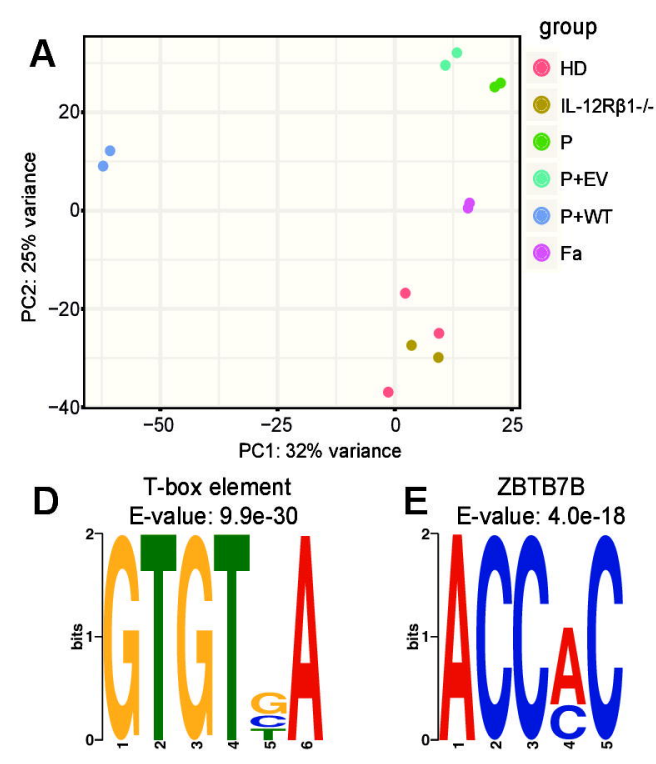

G
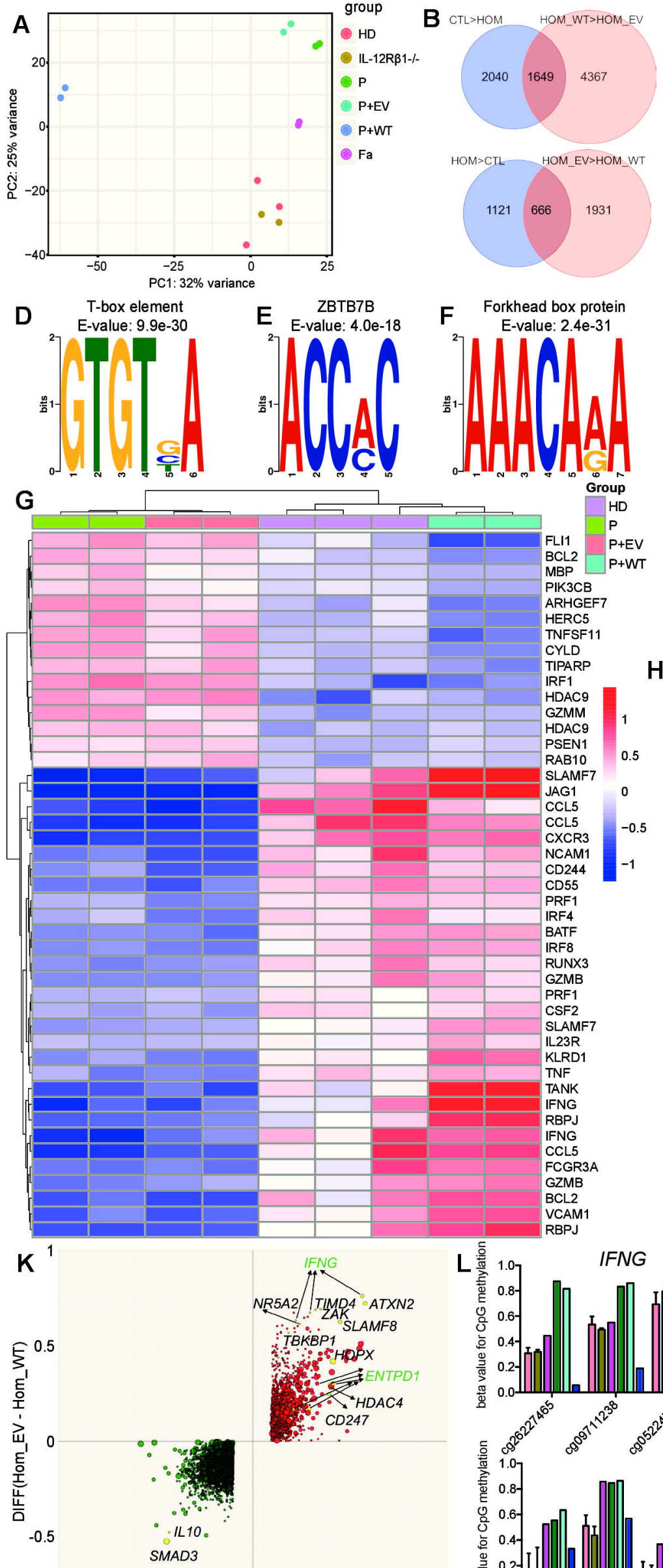

$-1$

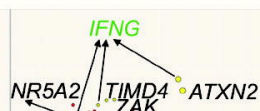

NRA2/.T ZAK SLAMFB
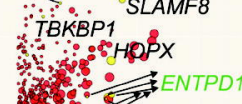

H.

6.: $C D 247$

SMAD3

\section{F E-value: $2.4 \mathrm{e}-31$}

roup

$P+E V$
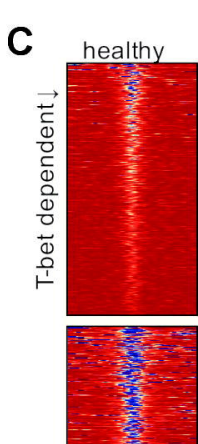

(n)
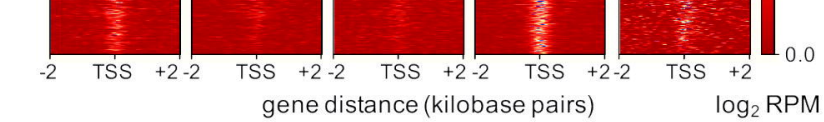

H chr12:68,551kb I chr6:31,542kb J chrX:70,835kb $5 \mathrm{~kb}$ $-68,559 \mathrm{~kb} \quad 1 \mathrm{~kb}-31,547 \mathrm{~kb} \quad \underline{1 \mathrm{~kb}}-70,845 \mathrm{~kb}$
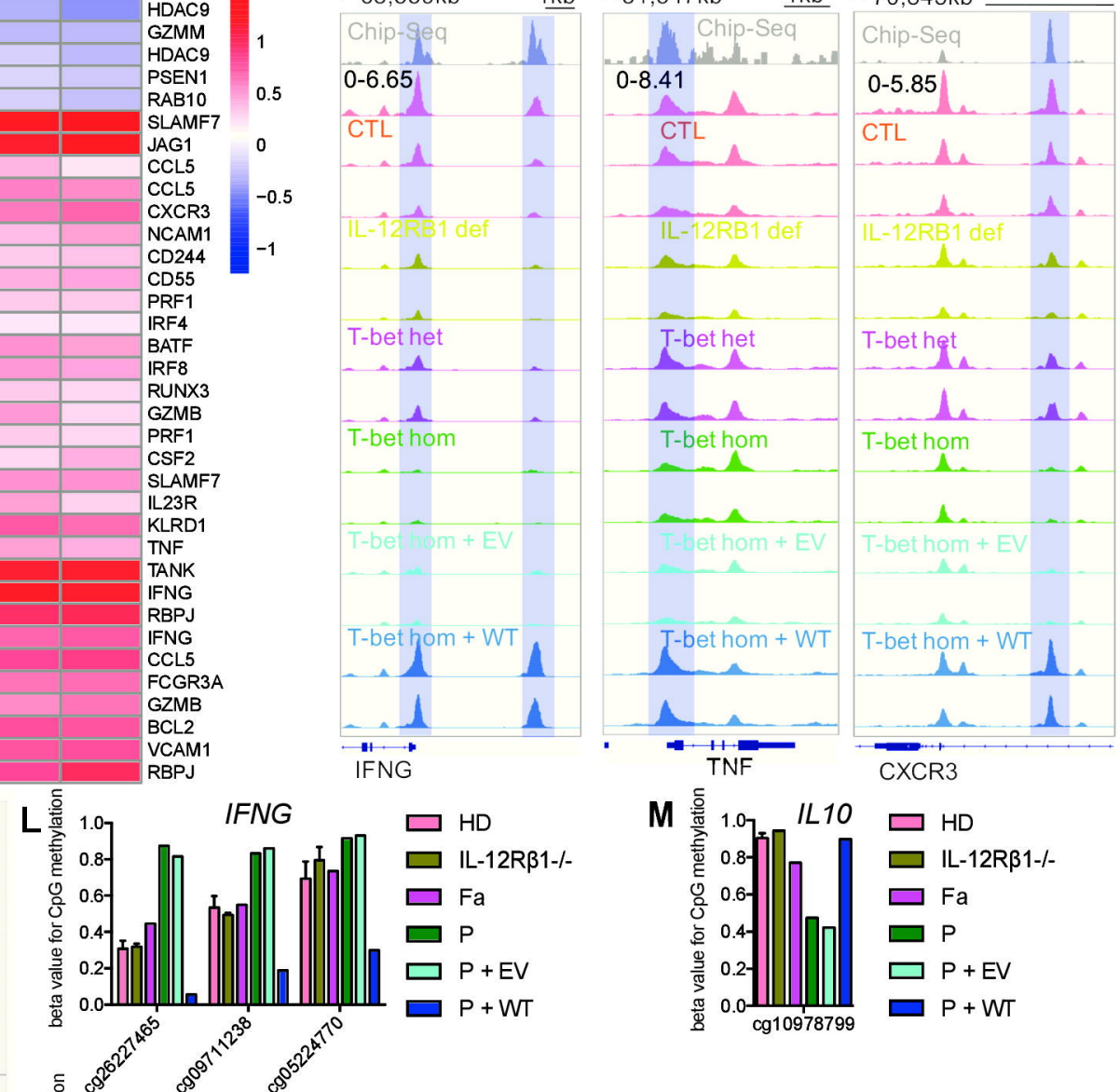

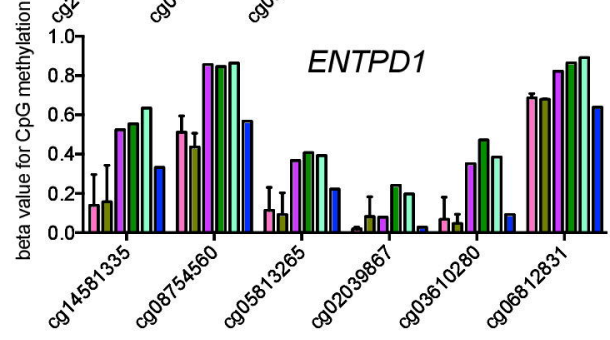


bioRxiv preprint doi: https://doi.org/10.1101/2020.08.31.274589; this version posted August 31, 2020. The copyright holder for this preprint (which was not certified by peer review) is the author/funder, who has granted bioRxiv a license to display the preprint in perpetuity. It is made

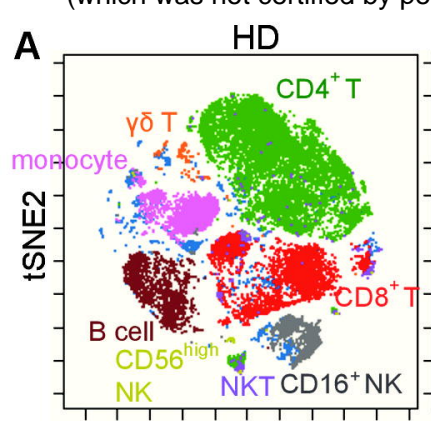

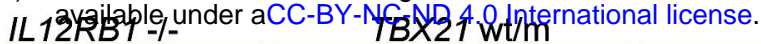

C
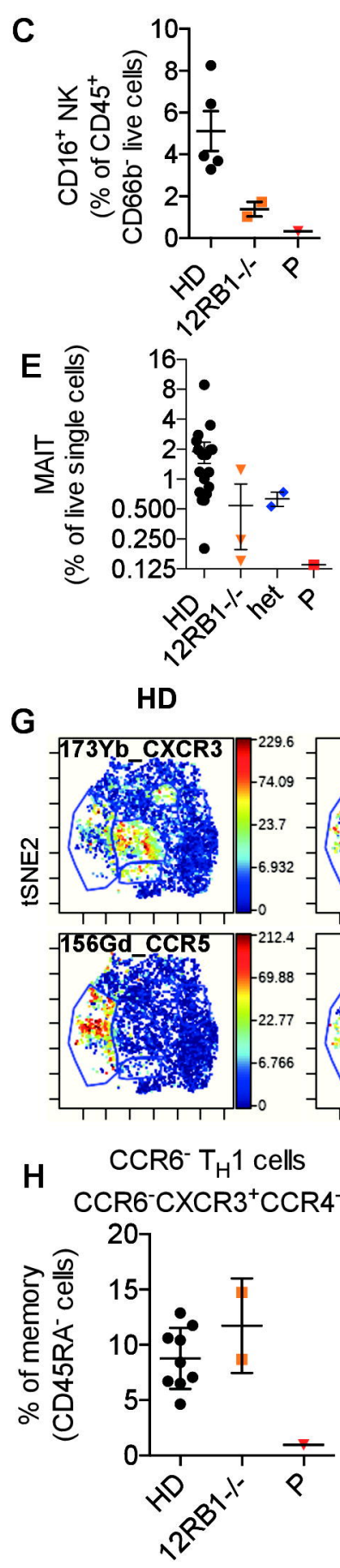
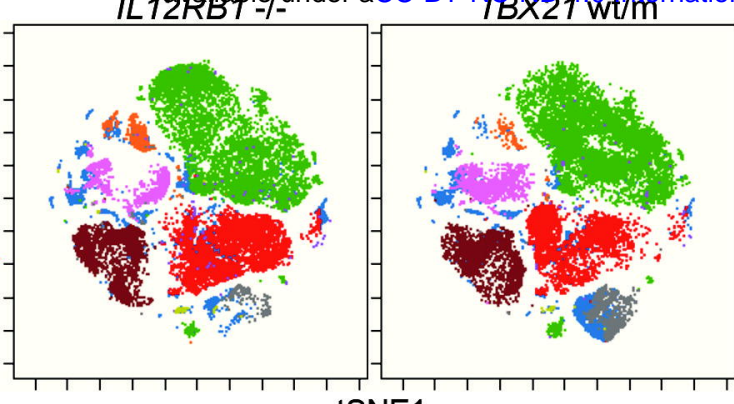

tSNE1
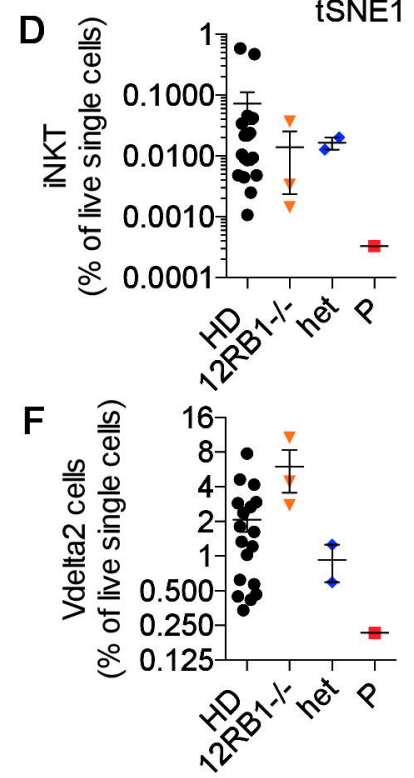

IL12RB1-/-

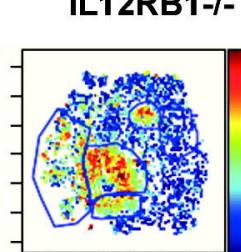

subset $3^{P}$ subset 4

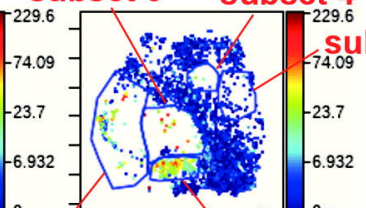

subsell surbset2

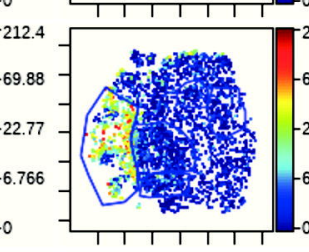

tSNE1
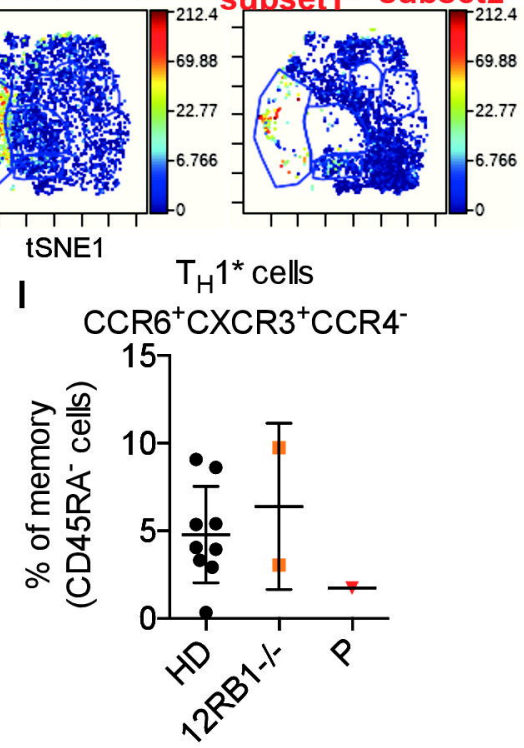

IL6 -

ANXA1
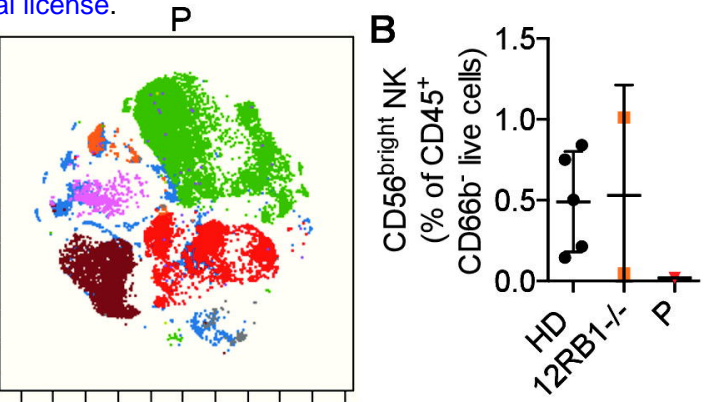

$\%$ expressing

cells

O 10

○ 20

30

40

50

Log2 ratio

(patient/control)

LINCO2446 - -000000

LGALS3 - $-0 \circ 000$

KLRB1- $\bigcirc \quad \circ \quad \bigcirc \quad \bigcirc \bigcirc \circ$

2
0
-2
-4

IL1B- 0 O 00000

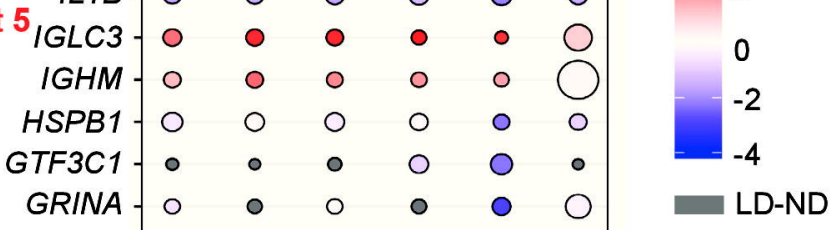

GADD45A - 00000

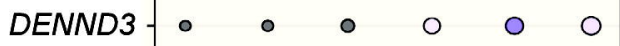

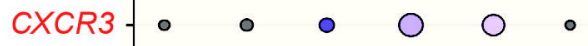

CTSW - 0000000

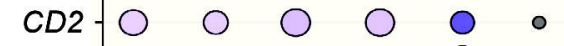

CCL4-O 0 O 0 ○ $\bigcirc 0$

CCLSL1-0 000090

CCL3 $-O \bigcirc \bigcirc \bigcirc \bigcirc \bigcirc$

c15orf48 - $0 \quad 0 \quad 00000$

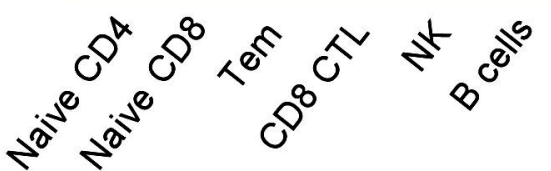

Figure 4 

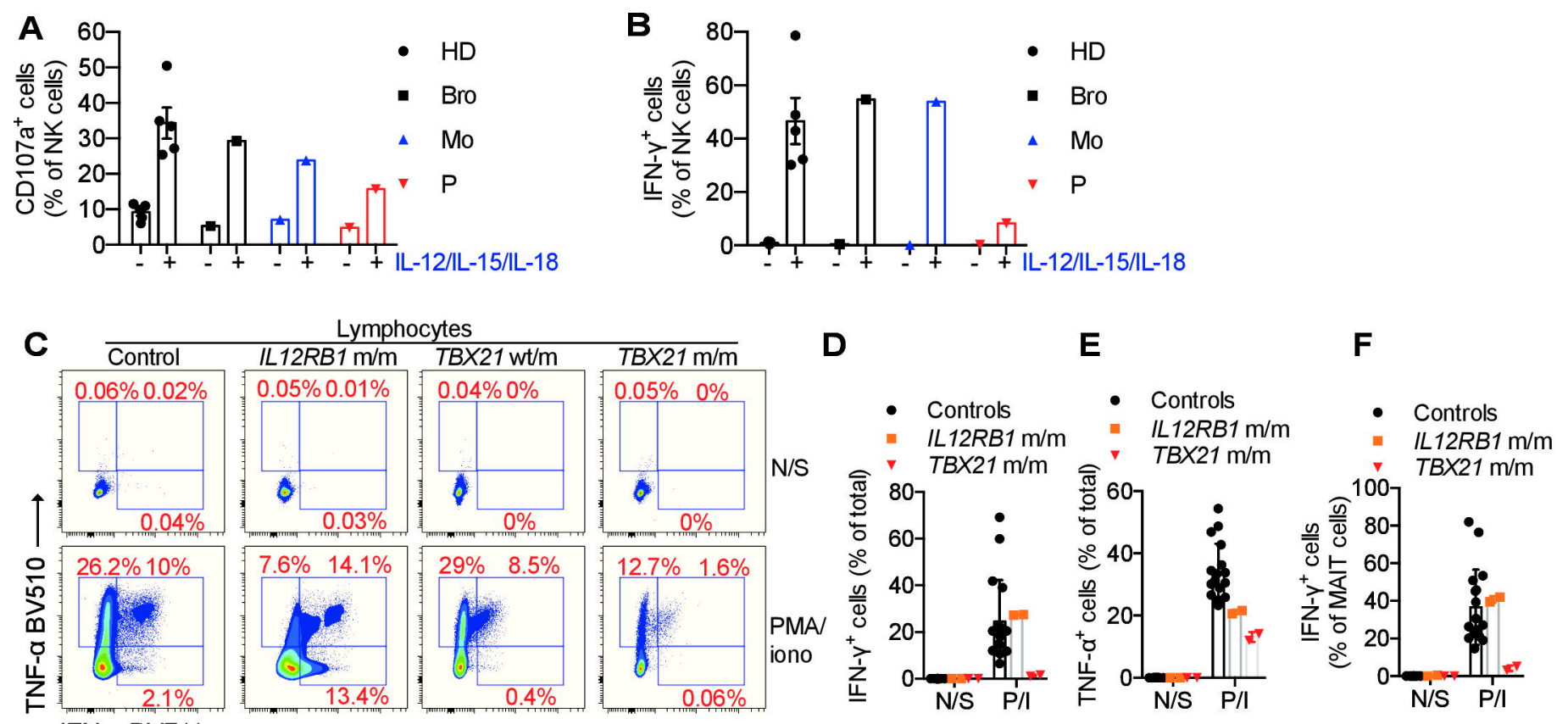

IFN-Y BV711 $\longrightarrow$
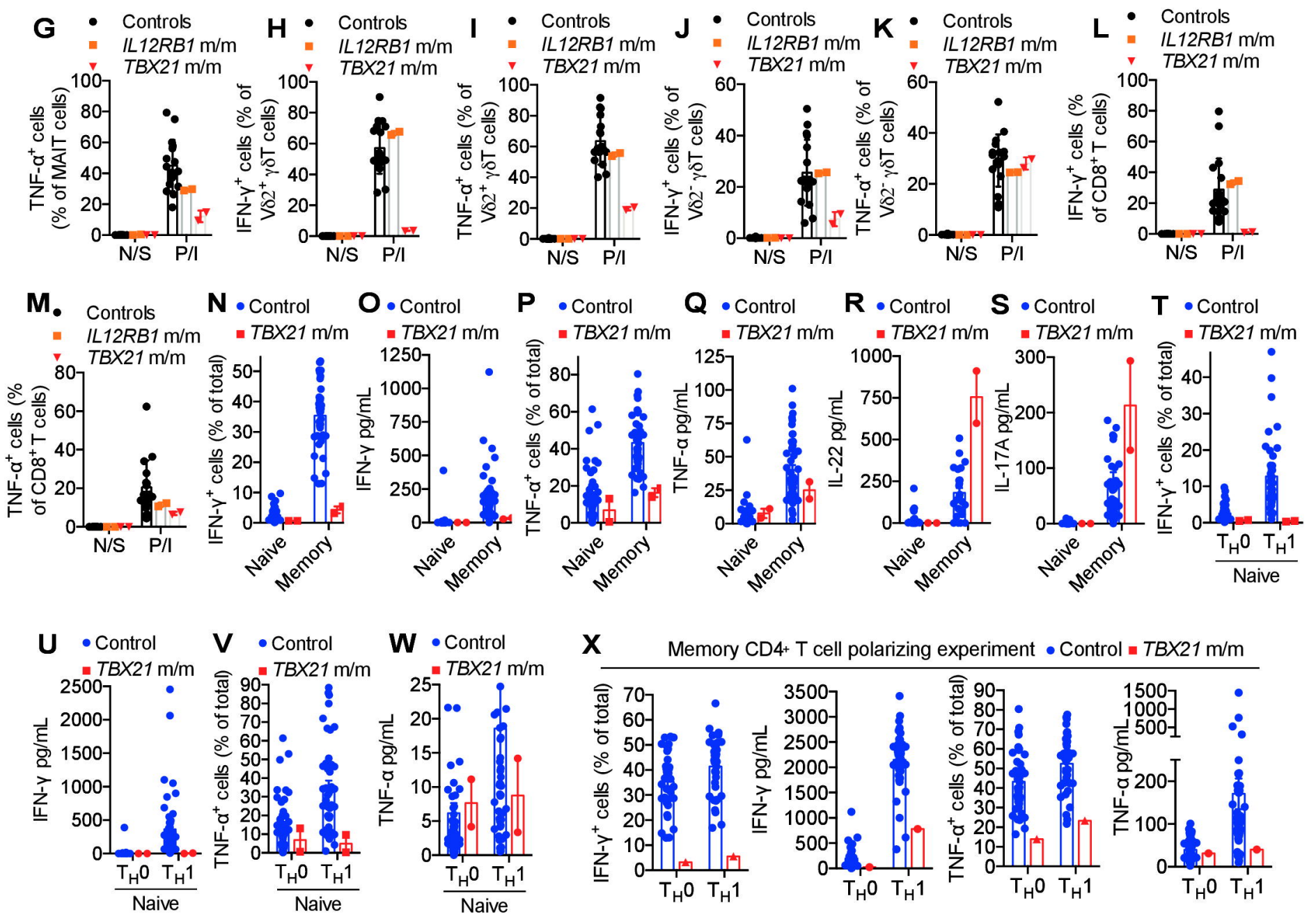
bioRxiv preprint doi: https://doi.org/10.1101/2020.08.31.274589; this version posted August 31, 2020. The copyright holder for this preprint (which was not certified by peer review) is the author/funder, who has granted bioRxiv a license to display the preprint in perpetuity. It is made available under aCC-BY-NC-ND 4.0 International license.
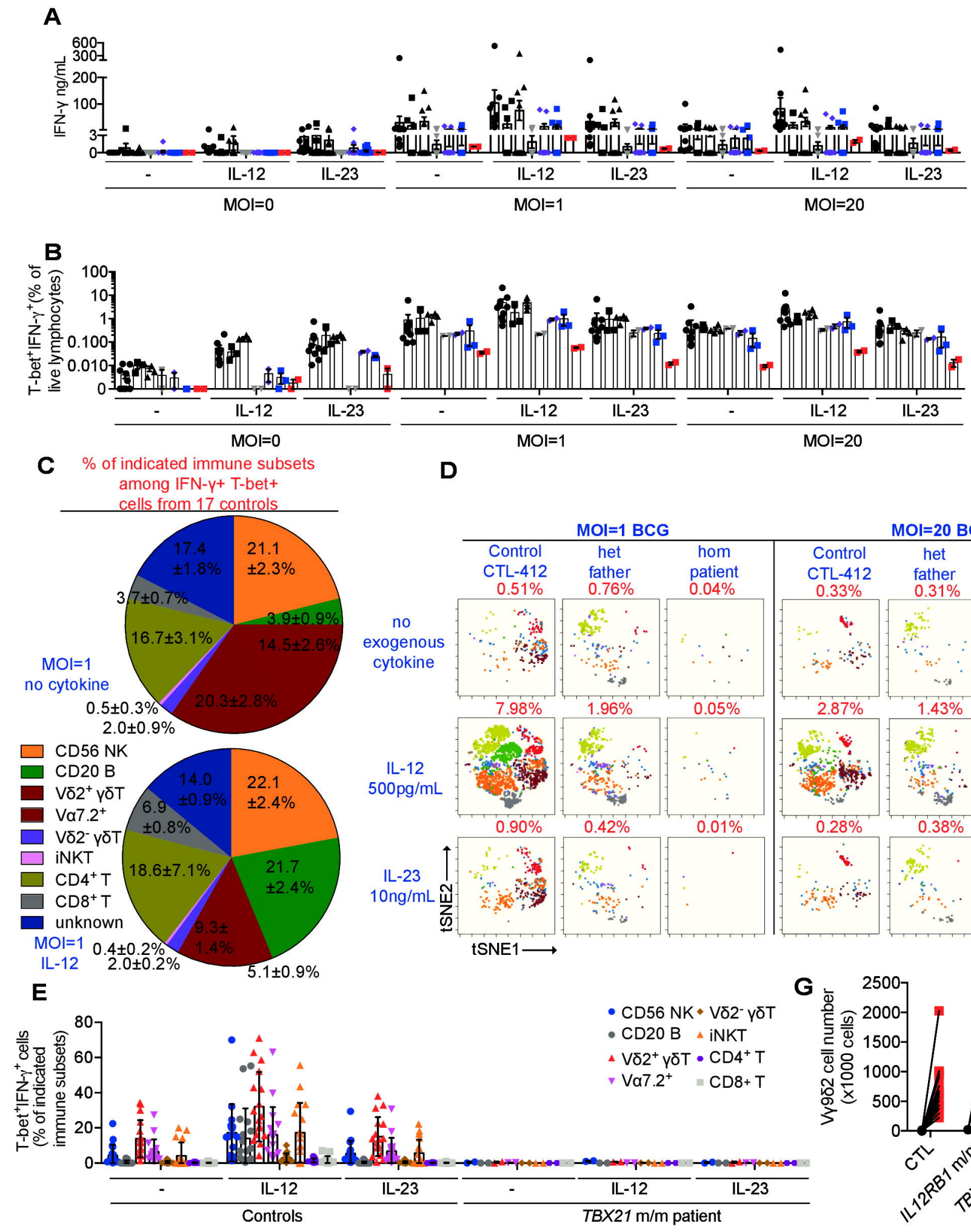

- Healthy

- Local controls

$\triangle \mathrm{BCG}$ vaccinated

$\checkmark / L-12 R B 1 \mathrm{~m} / \mathrm{m}$

- TBX21 wt/wt brother

- TBX21 wt/m parents - TBX21 m/m Patient IL-12 or IL-23 BCG infection (MOI)

- Healthy

- Local controls

$\triangle B C G$ vaccinated

- IL-12RB1 m/m

- TBX21 wt/wt brother

- TBX21 wt/m parents

- TBX21 m/m Patient IL-12 or IL-23

BCG infection (MOI)

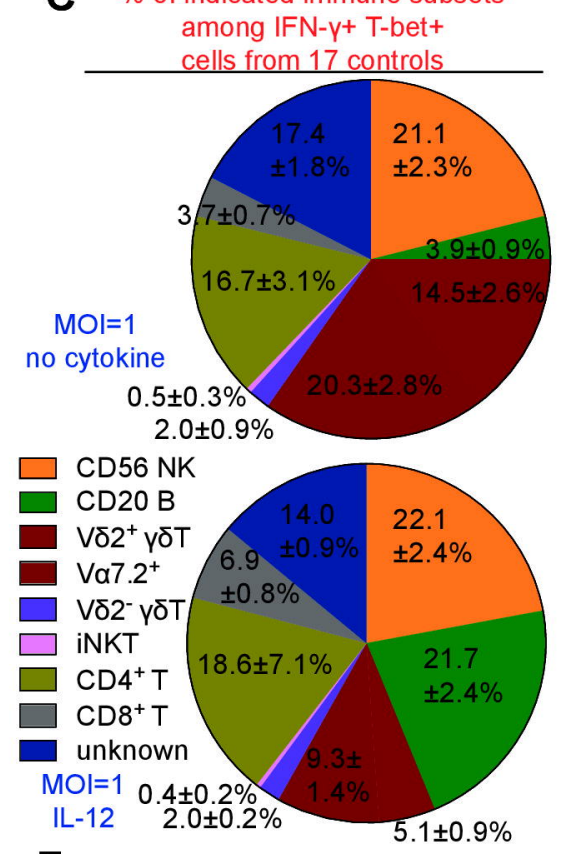

E

$\mathbf{F}$

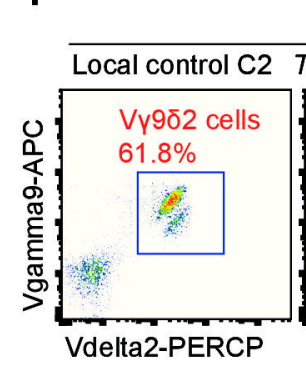

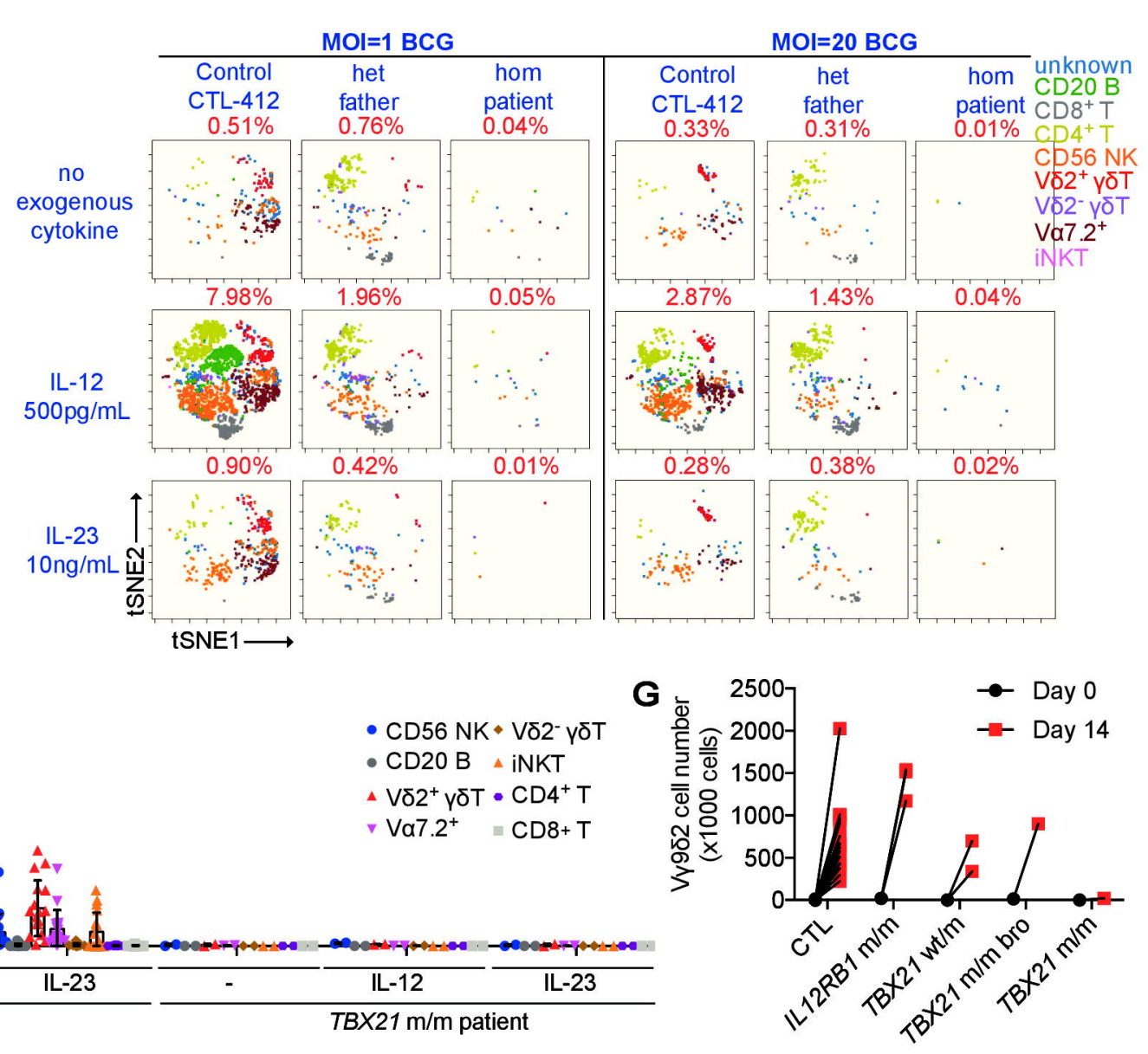

H

gated on CD3+ lymphocytes from different individuals

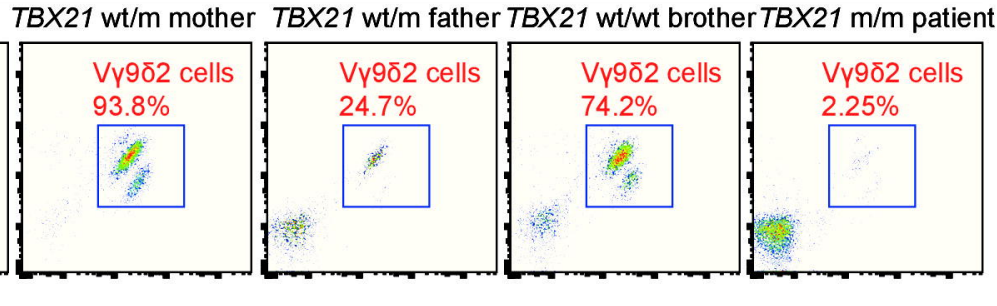

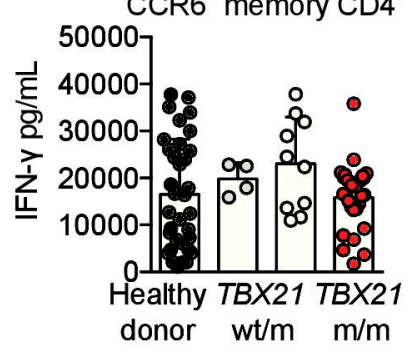

